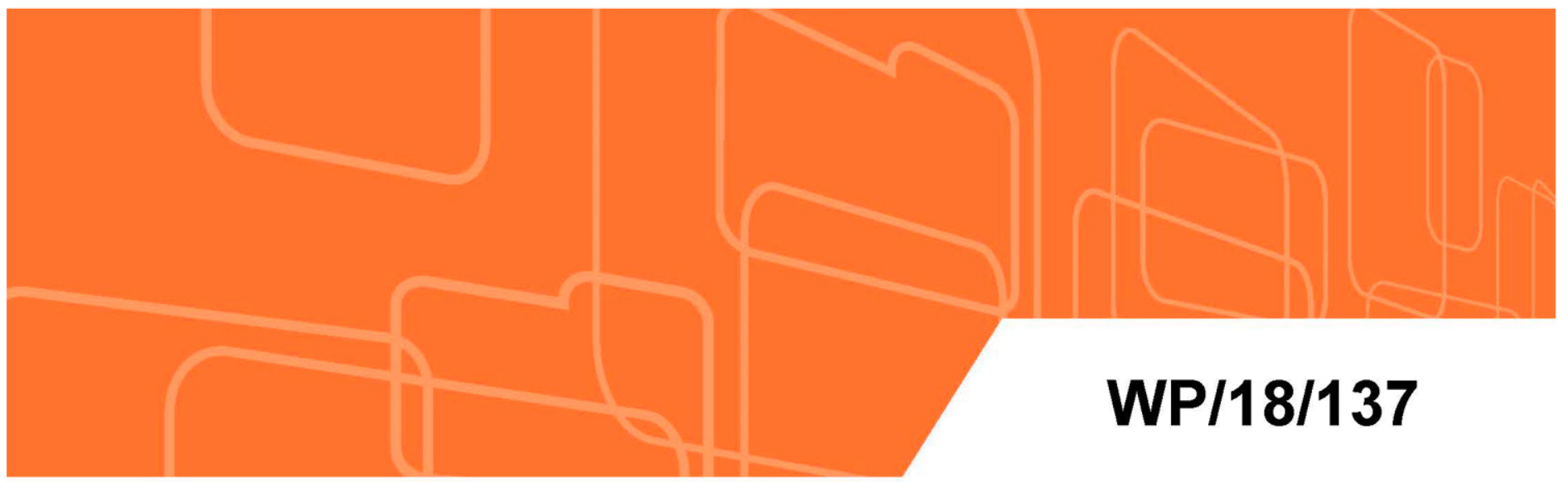

\title{
Global Market Power and its Macroeconomic Implications
}

by Federico J. Díez, Daniel Leigh, and Suchanan Tambunlertchai

IMF Working Papers describe research in progress by the author(s) and are published to elicit comments and to encourage debate. The views expressed in IMF Working Papers are those of the author(s) and do not necessarily represent the views of the IMF, its Executive Board, or IMF management. 


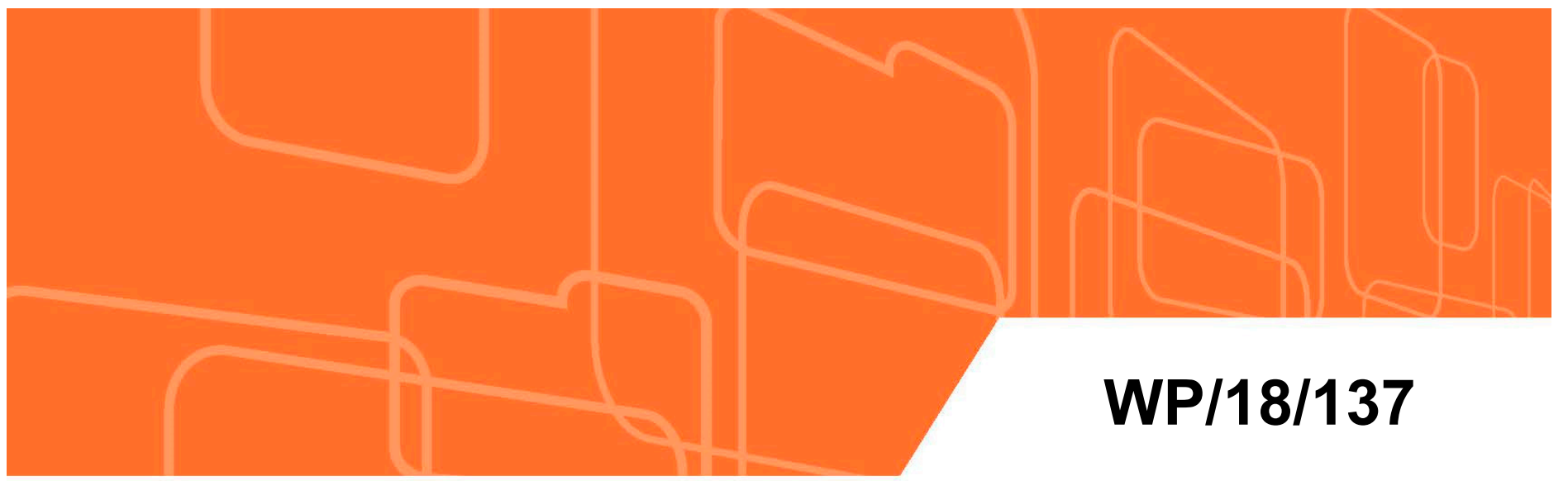

\section{IMF Working Paper}

\section{Global Market Power and its Macroeconomic Implications}

by Federico J. Díez, Daniel Leigh, and Suchanan Tambunlertchai

IMF Working Papers describe research in progress by the author(s) and are published to elicit comments and to encourage debate. The views expressed in IMF Working Papers are those of the author(s) and do not necessarily represent the views of the IMF, its Executive Board, or IMF management. 


\title{
IMF Working Paper
}

Western Hemisphere Department and Research Department

\section{Global Market Power and its Macroeconomic Implications}

\author{
Prepared by Federico J. Díez, Daniel Leigh, and Suchanan Tambunlertchai
}

Authorized for distribution by Nigel Chalk and Romain Duval

June 2018

\section{IMF Working Papers describe research in progress by the author(s) and are published to} elicit comments and to encourage debate. The views expressed in IMF Working Papers are those of the author(s) and do not necessarily represent the views of the IMF, its Executive Board, or IMF management.

\begin{abstract}
We estimate the evolution of markups of publicly traded firms in 74 economies from 19802016. In advanced economies, markups have increased by an average of 39 percent since 1980. The increase is broad-based across industries and countries, and driven by the highest markup firms in each economic sector. For emerging markets and developing economies, there is less evidence of a rise in markups. We find a positive relation between firm markups and other indicators of market power, such as profits or industry concentration. Focusing on advanced economies, we investigate the relation between markups and investment, innovation, and the labor share at the firm level. We find evidence of a non-monotonic relation, with higher markups being correlated initially with increasing and then with decreasing investment and innovation rates. This non-monotonicity is more pronounced for firms that are closer to the technological frontier. More concentrated industries also feature a more negative relation between markups and investment and innovation. The association between markups and the labor share is generally negative.
\end{abstract}

JEL Classification Numbers: D2, D4, E2, J3, K2, and L1.

Keywords: Market power, markup, concentration, investment, innovation, labor share.

Author's E-Mail Address: FDiez@imf.org, DLeigh@imf.org, STambunlertchai@,imf.org. 
A. Specification and data

B. Markups in the United States

C. Markups in 74 economies

D. Markups and Market Power

A. Investment and Innovation

B. Extensions

FIGURES

1. United States: Evolution of Estimated Markups

2. U.S. Firms: Markups in 2016 vs. 1980 by Economic Sector $\frac{21}{22}$

3. U.S. Firms: Distribution of Markups, 1980 and 2016.

4. Estimates of Output Elasticity Over Time

5. Estimated Markups for U.S. Firms: Baseline and Alternative Approach $\underline{24}$

6. Evolution of Estimated Markups Across Economies $\frac{25}{26}$

7. Firms in 31 Other AEs: Distribution of Markups, 1980 and 2016. $\underline{26}$

8. Investment Rate vs. Markup and Market Concentration. Estimation Results for U.S. Firms

9. Estimated Markup Coefficient vs. Market Concentration 28

10. Estimated Contribution of Markups to Investment Rate $\frac{29}{30}$

11. Investment Rate vs. Markup by Distance to Technology Frontier $\underline{30}$

\section{TABLES}

1. Relation Between Markup and Other Measures of Market Power $\underline{31}$

2. U.S. Firm-level Investment Rate Equation Estimates

3. U.S. Firm-level R\&D Rate Equation Estimates $\underline{33}$

4. U.S. Firm-level Labor Share Equation Estimates $\underline{34}$

5. U.S. Firm-level Labor Share Equation Estimates

6. Firm-level Equation Estimates for the United States and Other AEs $\underline{36}$ 


\section{INTRODUCTION ${ }^{1}$}

Rising corporate market power has become a prominent public policy issue in recent years. Corporate mergers and acquisitions featuring large high-technology firms have triggered intense debates regarding their effects. Some argue that corporate consolidation is reducing economic dynamism and exacerbating income inequality. Others argue that market dominance and the associated profits and economies of scale and scope are spurring investment and innovation. There is also little consensus on whether there has been a global increase in corporate market power across a range of advanced economies (AEs) and emerging markets and developing economies (EMDEs) or whether it is primarily a feature of high-technology U.S. firms. In this paper, to shed light on these issues, we estimate the evolution of market power for firms in 74 economies, and investigate how it relates to their investment and innovation decisions.

The lack of consensus on the extent and effects of market power partly reflects the difficulties in measuring it. A standard definition of market power is the ability of a firm to maintain prices above marginal cost — the level that would prevail under perfect competition. Since data on prices and marginal costs are generally unavailable for large numbers of firms over time, much of the existing work focuses on measuring market power using sales concentration ratios at the industry level. ${ }^{2}$ Such industry indicators do not, however, directly measure the margin between a firm's prices and marginal costs. Moreover, greater concentration in an industry (at the country level) does not always signal that firms have stronger market power, as in the case of firms selling an undifferentiated commodity that is priced internationally. The threat of potential entry can deter firms in concentrated industries from exercising market power by raising markups (Baumol, 1982). The difficulties of defining what constitutes a relevant industry where firms compete for customers exacerbate the limitations of such industry-level indicators, especially during periods of structural change. Overall, there has been little work on the evolution of firm-level indicators of market power. A recent exception is the pioneering work for U.S. firms by De Loecker and Eeckhout (2017) on which this paper partly builds. ${ }^{3}$

\footnotetext{
${ }^{1}$ We are grateful to Helge Berger, Nigel Chalk, Romain Duval, Jan Eeckhout, William Galston, Kotaro Ishi, Cheng Hoon Lim, Krishna Srinivasan, Maurice Obstfeld, Alejandro Werner, and numerous IMF seminar participants for helpful comments and discussions, to Peter Williams for excellent research assistance, and to Patricia Delgado and Javier Ochoa for superb editorial support.

${ }^{2}$ See, for example, Council of Economic Advisers (2016) and Autor and others (2017), who measure market power based on measure of sales concentration at the industry level, such as total sales of the four largest firms in an industry, the fraction of sales accrued by the 20 largest firms, and the Herfindahl-Hirschman index. See Shapiro (2017) for a critique of such industry-level concentration indicators.

${ }^{3}$ Recent papers on the macroeconomic impact of market power include Baquee and Farhi (2017) and Eggertson and other (2018).
} 
The lack of consensus also reflects the fact that theory provides an ambiguous guide. Traditional models predict that firms with more market power restrict production to raise prices. It is also plausible, however, that intense competition (less market power) and the slim associated profit margins, limit incentives to invest, including in technological innovation. Aghion and others (2005), for example, propose a model in which there is an inverted U-shaped relation between market competition and innovation. Initially, the "escape competition" incentive dominates and innovation increases with competition. At higher levels of market competition, however, innovation decreases, as the potential payoffs (postinnovation rents) decline.

To shed light on these issues, we estimate markups between prices and marginal costs for publicly traded firms in 33 AEs and 41 EMDEs from 1980-2016. This is the first study, to our knowledge, to report firm-level markups for such a broad range of economies over such an extended period. We measure markups by building on the approach of De Loecker and Eeckhout (2017) who use Compustat data on U.S. publicly traded firms. We extend the approach using an international dataset of publicly traded firms - Thomson Reuters Worldscope - and obtain more than 631,000 estimates of firm markups over 37 years for the 74 economies. As we explain in Section II, our markup estimation involves computing the ratio of firm sales to the cost of variable inputs, scaled by the output elasticity of variable inputs. ${ }^{4}$ The necessary data come from the published balance sheets and income statements of each publicly traded firm.

A limitation of our focus on publicly traded firms is that their behavior may be systematically different from privately held firms. Related work by Díez and others (2018) suggests that privately held companies have seen a smaller rise in markups than publicly held firms. However, the firms in our sample account for a large share of economic activity and thus cast light on macroeconomically relevant developments. For 2016, the U.S. firms in the sample have sales equivalent to 79 percent of U.S. GDP. For the other 73 economies in the sample, firms have sales equivalent, on average, to 75 percent of their respective economy's GDP.

Our estimates suggest that markups of publicly traded firms have generally increased during 1980-2016, especially in AEs. For AEs, the markups have increased by a GDP-weighted average of 39 percent since 1980. The increase is evident across countries and major industries, not only in high-technology ones. In economies where markups have increased, the rise has been driven by firms able to extract especially high markups, and the distribution of markups has widened. In EMDEs, there is less evidence of a rise in markups. The estimation results on the evolution of markups across countries hold up to robustness tests regarding the estimation approach. We also find a positive relation between markups and other indicators of market power, such as indicators of profits and industry sales

\footnotetext{
${ }^{4}$ For our baseline results, we measure the variable inputs with the cost of goods sold (COGS). Our findings are robust to controlling for additional operational costs such as selling, general, and administrative expenses (SGA).
} 
concentration. We do not assess in this paper, and leave for future analysis, the underlying causes of the rise in markups, which could, for example, reflect technological change or changes in antitrust regulation.

Next, we investigate the relation between markups and investment and innovation at the firm level. We start by focusing on data for the United States and then extend the analysis to 32 other advanced economies. We investigate the relation with firm-level investment and innovation rates by estimating standard "Tobin's Q" models for capital expenditure and research and development (R\&D) expenditure. We augment these equations with our firmlevel markups. The equations we estimate include numerous fixed effects, which allow us to isolate the relation of our variables of interest with markups, after accounting for features of individual firms and broader economic developments over time.

Our estimation results indicate a non-monotonic relation between markups and investment. Higher markups are associated with initially increasing and then decreasing investment and innovation rates. The results are strongly significant and robust, including to applying an instrumental variables approach to address potential reverse-causality concerns. The relation between markups and investment and innovation rates is also more strongly negative in industries featuring higher degrees of market concentration. These results are broadly consistent with the inverted U-shape prediction of the theoretical model proposed by Aghion and others (2005).

Finally, we extend our analysis in three directions. We investigate whether the inverted Ushape relation between markups and investment is steeper for firms that are closer to the technological frontier, as predicted by Aghion and others (2005), finding support for this hypothesis. We also investigate the relation between the firm-level labor share and markups, finding new firm-level evidence in support of the prediction of Autor and others (2017) that the labor share of income declines in industries where market power rises. Finally, we establish that our main estimation results also hold for firms in 32 other AEs.

The contribution of this paper is thus twofold. First, it presents evidence on the evolution of firm-level market power for a large set of countries over several decades. Second, it investigates how this evolution relates to firms' investment and innovation decisions, providing a multi-country, firm-level assessment. The rest of the paper is organized as follows. Section II presents our estimates on the evolution of market power internationally. Section III relates the evolution of the markup estimates to investment, innovation, and the labor share. Section IV concludes by discussing possible implications of the results for economic policy. 


\section{Evolution OF MARKUPS}

\section{A. Specification and data}

We estimate firm-level markups by extending the approach of De Loecker and Warzynski (2012) to a multi-country sample. ${ }^{5}$ The approach computes each firm's markup - the ratio of price to marginal cost $(\mu=P / M C)$ - as the ratio of sales to variable input expenditures, scaled by the variable inputs' estimated output elasticity.

The underlying theory starts from the firm's cost minimization problem. ${ }^{6}$ Firms are assumed to have a production function given by $Q=\Omega F\left(x_{1}, \ldots, x_{n}\right)$ where $Q$ refers to the units of output, $\Omega$ is the Hicks-neutral productivity level, and $x_{i}$ indexes the different inputs used in the production of $Q$. The first-order condition with respect to flexible (variable) input $x_{i}$ can be written as follows:

$$
P_{x_{i}}=\lambda \frac{\partial Q}{\partial x_{i}}
$$

where $P_{x_{i}}$ refers to the price of input $x_{i}$ and $\lambda$ is the Lagrange multiplier of the cost minimization problem and, therefore, represents the marginal cost. Based on the aforementioned definition of the markup, $\mu$, we can divide and multiply by the price of output, $P$, to obtain the following expression for the markup:

$$
\mu=\frac{\partial \ln Q}{\partial \ln x_{i}} \frac{P_{Q} Q}{P_{x_{i}} x_{i}}
$$

The markup thus equals to the output elasticity of input $x_{i}$ times the ratio of sales to expenditure on input $x_{i}$. The latter term can be observed directly from the firm-level data, while the former term has to be obtained by estimating a production function equation. We turn to these issues next.

Our data come from the Thomson Reuters Worldscope database, which contains the data we need to estimate markups based on published balance sheets and income statements for publicly traded firms in 74 countries. Table A1 lists the countries in our sample. The data span 1980-2016. For each firm, we observe its sales, the cost of goods sold (COGS), and its property, plant and equipment that we use as a proxy for the capital stock. Table A2 reports sample summary statistics for selected firm-level data.

Based on these variables, we specify a Cobb-Douglas production as follows (for simplicity of notation, we abstract from indexing firms):

\footnotetext{
${ }^{5}$ DeLoecker and Warzynski (2012) build on the work of Hall (1988). De Loecker and Eeckhout (2017) also use this approach.

${ }^{6}$ The advantage of this approach is that it does not require specifying a demand system describing how firms compete and set their prices. At the same time, it assumes that input markets are competitive. See De Loecker and others (2016) for an analysis with non-competitive input markets.
} 


$$
q_{t}=\beta_{x} x_{t}+\beta_{k} k_{t}+\omega_{t}+\epsilon_{t}
$$

where lower case letters denote logs and $q, x, k, \omega$, and $\epsilon$ index output (sales), COGS, capital, total factor productivity (TFP), and an error term, respectively. ${ }^{7}$ The coefficient $\beta_{x}$ represents the output elasticity of the composite variable input COGS and is the parameter needed in the markup equation (2).

To estimate the production function, we adopt a control function approach to address endogeneity concerns due to the potential simultaneity between unobserved productivity shocks and the demand for inputs. If the demand for an input increases with productivity shocks, that input's demand function can be inverted and the unobserved productivity shocks can be derived as a function of observables.

Our procedure follows closely Ackerberg, Caves, and Frazer (2015) and De Loecker and Warzynski (2012). We first assume that the demand for $x$, the composite variable input (COGS), depends on productivity $x_{t}=f\left(\omega_{t}, k_{t}\right)$. We can thus invert it, write it as $\omega_{t}=$ $f^{-1}\left(x_{t}, k_{t}\right)$, and enter it into the production function as follows:

$$
q_{t}=\beta_{x} x_{t}+\beta_{k} k_{t}+f^{-1}\left(x_{t}, k_{t}\right)+\epsilon_{t}=\phi\left(x_{t}, k_{t}\right)+\epsilon_{t},
$$

where $\phi$ can be estimated using any consistent non-parametric estimator. We assume that productivity follows a first-order Markov process, which we specify as $\omega_{t}=E\left(\omega_{t} \mid \omega_{t-1}\right)+$ $\eta_{t}$, where the last term, $\eta_{t}$, is an innovation to the firm's productivity process. Solving for $\eta_{t}$, and replacing $\omega_{t}$ with the first-stage estimates already mentioned, we have

$$
\hat{\eta}_{t}=\hat{\phi}_{t}-\beta_{x} x_{t}-\beta_{k} k_{t}-\hat{E}\left(\hat{\phi}_{t-1}-\beta_{x} x_{t-1}-\beta_{k} k_{t-1}\right) .
$$

The value for $\beta_{x}$ (and $\beta_{k}$ ) can be recovered through a standard GMM procedure. Under the assumption that the input $x$ responds to current productivity shocks but its lagged values do not, we obtain the following moment condition:

$$
E\left(\begin{array}{c}
\eta_{t} x_{t-1} \\
\eta_{t} k_{t}
\end{array}\right)=0
$$

from which we obtain $\beta_{x}$ and $\beta_{k}$ (and from which we can recover TFP, $\omega_{t}$ ). We estimate the output elasticities for the 19 super-sectors of the FTSE/Dow Jones Industrial Classification Benchmark (ICB) available within Thomson Reuters Worldscope. ${ }^{8}$ Finally, based on these

\footnotetext{
${ }^{7}$ We deflate $q$ and $x$ using the deflator for value added in the firm's economic sector, based on sectoral data taken from the OECD STructural ANalysis (STAN) database. We deflate $k$ using the aggregate investment price deflator taken from the World Bank World Development Indicators (WDI) database.

${ }^{8}$ The ICB classification available in the Thomson Reuters Worldscope dataset allocates firms into 10 industries, which in turn include 19 super-sectors and 115 sub-sectors.
} 
output elasticity estimates, we re-write the equation for markups as $\mu_{t}=\beta_{x} \frac{x_{t}}{q_{t}}$, where the $\beta_{x}$ term is at the sector level, and the $\frac{x_{t}}{q_{t}}$ term is at the firm level.

As De Loecker and Warzynski (2012) explain, since data are available for the value of sales, rather than the quantity of sales, we can reliably identify the markup only up to a constant. Our discussion therefore focuses on the evolution of markups over time and on cross-section comparisons rather than on the absolute level of markups. ${ }^{9}$

\section{B. Markups in the United States}

We begin our analysis by looking at the evolution of markups in the United States. As Figure 1 reports, markups of U.S. firms have increased by a sales-weighted average of 42 percent during 1980-2016. ${ }^{10}$ Markups have increased across all major industries, and not only technology ones, with the sales-weighted average increase ranging between 7 and 137 percent for the 10 broad ICB industries available within Thomson Reuters Worldscope. To illustrate this broad-based increase, Figure 2 plots the sales-weighted average markups in 2016 against their level in 1980 for the 115 available ICB sub-sectors pertaining to the 10 industries. Sub-sectors in the "Technology" industry have seen a (sales-weighted) average markup increase of 46 percent, slightly above the U.S. economy-wide average. Other subsectors, such as those in the "Finance" or "Health Care" industries have seen larger increases, on average. The sub-sector featuring the largest increase in markups over this period (by 419 percent) is "Biotechnology," part of the "Health Care" industry.

At the same time, the distribution of markups has broadened and become more skewed upward over time. Figure 3 reports the distribution of markups in 1980 and 2016 for the 10 ICB industries. The rise in average markups is associated with especially large increases among the highest markup firms in each industry.

\section{Robustness}

We assess the robustness of our markup estimates along two dimensions. First, we relax the baseline assumption of a fixed technology (production function) for each industry over the sample. Second, we re-run our markup estimates with a richer production function specification.

\section{Time-Varying Technology}

A potential concern with our identification of markups is that the underlying technology (production function) is assumed to be constant, for each industry, throughout the entire

\footnotetext{
${ }^{9}$ We follow De Loecker and Eeckhout (2017) and correct the markup estimates for measurement error in sales data following the procedure described in De Locker and Warzynski (2012).

${ }^{10}$ The sales-weighted average markup (factor) rises from 1.12 in 1980 to 1.59 in 2016, implying a rise of 42 percent (1.59/1.12). This result is comparable to that of De Loecker and Eeckhout (2017) for the years 19802014 for which our samples overlap, which is reassuring, since we use a different dataset.
} 
sample. This implies that the $\beta_{x}$ coefficient we estimate for each industry is fixed over time. This assumption could be too restrictive if, for example, the labor- and capital-intensity of industries has shifted significantly over time, and could unduly influence the markup estimates.

To address this concern, we investigate the stability of the estimates for $\beta_{x}$. Specifically, we divide our time sample into two halves, 1980-1998 and 1999-2016, and re-estimate the production functions and the corresponding elasticity, $\beta_{x}$, for the two sub-samples. Figure 4 presents the estimates of $\beta_{x}$ for the two sub-samples for each industry. There is little evidence of the estimates of $\beta_{x}$ varying materially over time. Our baseline assumption of a constant technology throughout our sample period thus seems warranted and is unlikely to unduly influence our results for the evolution of markups.

\section{Production Function Inputs}

We consider an alternative assumption regarding the inputs included in the production function. As pointed out by Traina (2018), the variable COGS is a central component of the firm's operational expenditures, and the other component is Selling, General and Administrative Expenses (SGA). This SGA component covers non-production costs of the firm such as advertising and marketing and, more generally, overhead costs.

A potential concern is that our baseline approach may be driven by a change in the production technology towards greater fixed (overhead) costs and lower marginal costs. This would imply that the increase in markups reflects firms recouping their original down payments, rather than an increase in market power. To address this concern, we re-estimate our production function, explicitly incorporating SGA as an additional input. That is, we respecify our baseline equation (3) as follows:

$$
q_{i t}=\beta_{\text {cogs }} \operatorname{cog}_{i t}+\beta_{s g a} s g a_{i t}+\beta_{k} k_{i t}+\omega_{i t}+\epsilon_{i t}
$$

We re-compute our markups using the new estimates of the $\beta_{\text {cogs }}$ elasticities that control for the effect of shifts in SGA. We continue to estimate the markups using the COGS-elasticity since the procedure requires the input to be flexible (variable). It would thus not be appropriate to use SGA, as this is not a fully flexible input. ${ }^{11}$

The results suggest that controlling for SGA does not unduly influence the markup estimates. As Figure 5 illustrates, the markups estimated using this alternative approach are strongly correlated with markups estimated following our baseline approach. The sales-weighted average level of the markups controlling for SGA is below the baseline (due to the lower estimated elasticity values) and the increase over 1980-2016 is 35 percent. This increase is 17 percent smaller than the 42 percent increase based on the baseline measure that does not

\footnotetext{
${ }^{11}$ In the afore-mentioned derivation of the markup, the input $x$ is required to be flexible. Otherwise, identifying the markup would not be possible as part of the estimation procedure, as factors other than market power (such as adjustments costs) would be contaminating the results.
} 
control for SGA (35/42). We conclude that technological change associated with shifts in SGA accounts for a small part of the rise in markups.

\section{Markups in 74 economies}

As Figure 6 reports, the increase in markups has primarily occurred in AEs. There is less evidence of rising markups in EMDEs. ${ }^{12}$ For the group of 32 AEs excluding the United States, the GDP-weighted average of our estimated markups has increased by 35 percent since 1980, slightly less than for the United States (42 percent). The evolution of the estimated markups in Canada has been comparable to that of the United States. Estimated markups in Europe have, in general, mainly increased since 2000, while in Japan they have increased more moderately throughout the sample.

The increase in average markups for publicly traded firms in non-U.S. AEs is apparent across all 10 of the afore-mentioned broad industrial sectors. The sales-weighted average markups for these 10 broad industries have increased by 17-72 percent over 1980-2016. As in the United States, the rise in markups has, within each industry, been accompanied by an increasingly skewed distribution, with a small number of firms extracting especially high markups (Figure 7).

\section{Markups and Market Power}

A possible concern regarding our results is that the rise in firm-level markups reflects the need for firms to recoup fixed costs of investment into efficiency enhancing technology, rather than a rise in market power and associated profits. In this case, firms would keep the price per unit of output above the variable cost per unit to recoup the fixed cost, but extract little increase in overall profits. To further assess whether the rise in markups is driven by the need to recoup fixed costs, we investigate the relation between rising markups and overall profits.

We find a strong positive relation between markups and broad measures of profitability at the firm level, suggesting that the rise in measured markups has been associated with increased market power. ${ }^{13}$ On average, for firms in the United States and other advanced economies, a 10 percentage point rise in markups is associated with, respectively, 19 and 13 percentage point increases in the ratio of dividends to sales (Table 1). We find a similarly strong relation between markups and another measure of profitability, the market capitalization-to-sales

\footnotetext{
${ }^{12}$ This asymmetric pattern between AEs and EMDEs could, in principle, be associated with the rise of outsourcing and global value chains. AE-based firms moving part of their production to EMDEs or outside of the firm boundaries, could plausibly reduce their production costs, including COGS. However, such developments are unlikely to fully explain the AE-EMDE divergence in the markups, as our estimates of markups use consolidated data, including for COGS. Moreover, as already mentioned, the estimated rise in markups is robust to controlling for shifts along the COGS-SGA margin, including those that could result from outsourcing.

${ }^{13}$ The Thomson Reuters WorldScope dataset also contains data on the "profit margin" but this measures profits based on the cost of goods sold and is thus not relevant for assessing the evolution of overall firm profits.
} 
ratio. Our result for firms in the United States is consistent with the findings of De Loecker and Eeckhout (2017) using a different dataset and, furthermore, we find that the result also extends to other AEs.

We also find evidence, as Table 1 reports, that markups are positively related with market concentration. A standard measure of industry concentration is the Herfindahl-Hirschman index (HHI), defined as $H_{j t}=\sum_{i} s_{i j t}{ }^{2}$ where $s_{i j t}$ represents the sales of the $i$ th firm in the $j$ th market (industry) and year $t$ as a ratio of total market $j$ sales in year $t$. We construct an adjusted HHI index constructed for the 115 ICB sub-sectors available within Thomson Reuters Worldscope. Constructing the conventional HHI for our sample of publicly traded firms is complicated by the rise in the number of publicly traded firms in the sample for the 1990s. This increase is associated with numerous initial public offerings (IPOs) that reduce the market share $\left(s_{i j t}\right)$ of existing firms, implying — other things equal — a mechanical (spurious) reduction in market power. To address this issue, we construct a measure of sales concentration based on percentiles of the distribution of firm sales by sector for each year. For this adjusted HHI, the $s_{i j t}$ terms represent the sales of firms at each decile of the distribution of sales in sector $j$ and year $t$ as a share of the sum of the deciles in sector $j$ and year $t$. The index thus ranges from 0 to 1, as for the conventional HHI. As Table 1 reports, it is positively associated with our markup estimates.

These positive relations between markups and profitability, and between markups and concentration reinforce the interpretation that rising markups have reflected rising market power.

\section{MACROECONOMIC IMPLICATIONS}

To shed light on the macroeconomic implications of rising market power, we now investigate the relation between our firm-level markups and firm-level measures of economic performance. We focus on capital expenditure and R\&D spending for firms in the United States, the country for which we have the most complete data. As an extension, we investigate the implications of higher markups for the labor share at the firm level, and also extend the sample to other AEs.

\section{A. Investment and Innovation}

\section{Investment}

We first focus on the relation between a firm's market power and its investment decisions. The estimated equation has the firm's investment rate - capital expenditure as a share of the previous year's capital stock — as the dependent variable on the left-hand side. ${ }^{14}$ On the right-

\footnotetext{
${ }^{14}$ Capital expenditure is defined as the variable CapExp in the Thomson Reuters Worldscope dataset. The capital stock is defined as the variable PPE (property, plant, and expenditure) in the Thomson Reuters WorldScope dataset.
} 
hand side, the main explanatory variable of interest is the (log of the) firm-level markup. The equation is thus:

$$
Y_{i j t}=\beta \ln \mu_{i j t}+\sum_{x} \theta_{x} x_{i j t}+\sum_{i} \alpha_{i}+\sum_{t} \theta_{t}+\epsilon_{i j t}
$$

where $Y_{i j t}$ is the investment rate; $\mu_{i j t}$ is the markup; $i$ denotes the $i$ th firm; $j$ denotes the $j$ th economic sector based on the 19 ICB super-sectors in the Thomson Reuters Worldscope dataset; and $t$ denotes the year.

The equation controls for firm $\left(\alpha_{i}\right)$ and time $\left(\theta_{t}\right)$ fixed effects. The inclusion of these fixed effects allows us to isolate the relation with markups, after controlling for broader macroeconomic developments and features of individual firms. The equation also controls for a number of firm-specific factors, included in the $x$ terms. These controls include a measure of Tobin's Q, the sales rate, and the R\&D rate in the previous year. Following the literature, we calculate Tobin's Q as the sum of the market value of equity and the book value of debt divided by the book value of assets, based on Thomson Reuters Worldscope data. The R\&D and sales rates are defined, respectively, as the level of R\&D and sales as a share of the previous year's tangible and non-tangible (total) assets. ${ }^{15}$ The inclusion of these additional controls - in addition to the afore-mentioned fixed effects - mitigates but does not eliminate the possibility of endogeneity. In particular, reverse causality between investment and markups at the firm level could remain. We investigate this issue using instrumental variables in the section on robustness below, finding results that are qualitatively similar to those obtained using our baseline (OLS) estimation procedure.

To test for the presence of non-linear relations, we estimate equation (8) while interacting the firm-level markups with the level of markups and with the degree of sector-level market concentration, measured by the adjusted HHI index. This adds two interaction terms to the equation: $\delta\left\{\ln \mu_{i j t} \times \ln \mu_{i j t}\right\}$ and $\gamma\left\{\ln \mu_{i j t} \times\right.$ Concentration $\left._{i g t}\right\} .{ }^{16}$ Our baseline measure of concentration is, as before, computed at the granular 115 ICB sub-sector level (the subscript $g$ indicates $s u b$-sectors). ${ }^{17}$

The estimation results, reported in Table 2, suggest a non-monotonic relation between investment and markups. Higher markups are initially associated with increasing investment,

\footnotetext{
${ }^{15} \mathrm{R} \& \mathrm{D}$ is defined as the variable RD in the Thomson Reuters Worldscope dataset. Total assets are defined as the variable TA in the Thomson Reuters WorldScope dataset.

${ }^{16}$ Our main explanatory variable of interest is the $\log$ of the firm markup, $\ln \mu_{i j t}$. The estimate of coefficient $\beta$ in equation (8) thus indicates rise in the investment rate for a 1 percent (in $\log$ points) rise in the markup. To investigate how this relation with a 1 percent rise in the markup depends on the $(\log )$ level of the markup we interact the $\ln \mu_{i j t}$ term with $\ln \mu_{i j t}$. Note that including a term $\ln \left(\mu_{i j t} \times \mu_{i j t}\right)$ in equation (9) would not be appropriate as it would be equivalent to $2 \ln \mu_{i j t}$ and thus be exactly multicollinear with the $\ln \mu_{i j t}$ term.

${ }^{17}$ To limit the influence of outliers, we apply 5 percent trimming to the data used in the analysis. We discard the 5 percent lowest and highest observations for the dependent and control variables based on their respective country-sector-year distributions.
} 
as indicated by the positive estimated coefficient on the markup (first row). At higher levels of markups, however, increases in markups become associated with lower investment, as indicated by the negative coefficient in the second row. This finding is consistent with the "inverted-U" relation between competition and investment posited by Aghion and others (2005), where pre-innovation rents rise faster than post-innovation rents at high levels of market power, implying weaker incentives to invest. ${ }^{18}$ Figure 8 illustrates how our estimates are consistent with this inverse U-shape. The figure reports the relation between markups (horizontal axis) and the fitted values of the investment rate (vertical axis). Furthermore, the estimated non-monotonic relation between markups and investment is not driven by any particular industry. Table A3 reports estimation results for the 10 ICB industries available in the Thomson Reuters WorldScope dataset obtained by interacting the respective coefficients with dummy variables indicating each ICB industry. The coefficient estimates for the industry dummies interacted with the quadratic markup are negative for all 10 of the ICB industries.

The results in Table 2 also imply that, as markets become more concentrated, higher markups are associated with lower investment. This non-linear relation is indicated by the positive coefficient estimate for the markup, and the negative coefficient estimates for the concentration index in column (2). As illustrated in Figure 9, for concentration index values above 0.5 , higher markups are associated with lower investment. The sub-sector market concentration index ranges from 0.1 to 1.0 in the sample. When the two markup interaction terms are included together in the estimated equation, both have statistically and economically significant coefficients (column 3).

To shed light on the macroeconomic significance of these findings, we calculate the share of U.S. firms for which rising markups are associated with lower investment. We derive the composite slope coefficient indicating the marginal association between investment and markups by differentiating equation (8) with respect to the (log) markup. The expression of interest is $\frac{d Y_{i j t}}{d \ln \mu_{i j t}}=\beta+\delta \ln \mu_{i j t}$ for the first specification reported in Table 2 (column 1). We compute the share of firms for which this expression is negative for all three specifications reported in Table 2 based on data for 1980 and 2016. As of 2016, higher markups are associated with lower investment for 8, 17, and 6 percent of U.S. publicly listed firms, across the three specifications, respectively. In contrast, no firms had a negative association between higher markups and investment as of 1980. Figure 10 illustrates these findings based on the most complete specification reported in Table 2 (column 3). ${ }^{19}$

\footnotetext{
${ }^{18}$ Aghion and others (2005) find support for the non-monotonic prediction of their model using industry-level data for the United Kingdom. To our knowledge, this is the first paper to present evidence of such a relation based on firm-level data.

${ }^{19}$ For the specification reported in column (3) of Table 2, the expression for the composite slope coefficient is $\frac{d Y_{i j t}}{d \ln \mu_{i j t}}=\beta+\delta \ln \mu_{i j t}+\gamma$ Concentration $_{i g t}$.
} 


\section{Innovation}

The estimation results for R\&D expenditure are qualitatively similar to those for physical investment. As Table 3 reports, there is also a non-monotonic relation between markups and $\mathrm{R} \& \mathrm{D}$ expenditure. The estimated equation is as before, except that the term $Y_{i j t}$ now denotes R\&D expenditure as a share of the previous year's total assets. ${ }^{20}$ Also as before, the coefficient estimates imply that higher markups are initially associated with increasing innovation expenditure, but at higher levels of markups, or at higher levels of market concentration, the marginal relation between innovation and markups becomes negative. These results are consistent with the view that firms have lower incentives to invest in innovation as their market position strengthens, as in the model of Aghion and others (2005).

\section{Robustness}

We now examine the effect of re-estimating our equations for investment and innovation using an instrumental variables approach. We also test the sensitivity of our results to including additional fixed effects to control for sectoral technological shocks and other sector-specific developments, and using an alternative measure of market concentration.

We first address the concern that higher investment or R\&D rates of the $i$ th firm might raise markups of the $i$ th firm, implying reverse causality. To investigate whether this source of endogeneity is driving the baseline results, we re-estimate equation (8) while instrumenting the markup of the $i$ th firm with the median markup of the other firms in the same ICB subsector (excluding $i$ th firm). The markup interaction term is instrumented similarly, using the product of the median markup of the other firms. The first stages are strong: each first-stage equation has an F-statistic on the excluded instruments with a p-value well below 0.001 percent, indicating that the instruments have strong explanatory power. The second stage estimation results, reported in Table A4, are quantitatively similar to the baseline OLS results, and provide reassurance that reverse causality is not driving the baseline results.

Next, we examine the effects of including additional fixed effects in the estimated equation. We add sector-year fixed effects to capture sector-specific developments over time, such as sector-specific technological change. This change implies the addition of the terms $\sum_{j t} \theta_{j t}$ to equation (8). As reported in Table A5, the addition of this additional fixed effects has little effect on the results.

Finally, we investigate the sensitivity of the finding that the coefficient on the interaction term related to concentration is negative to measuring market concentration based on an alternative version of the HHI index. To address changes in the number of publicly listed firms in the sample over time due to shifts in public ownership, this alternative is based on computing the squared shares of sales of firm $i$ in sector $j$ in year $t$ as a ratio of the sector $j$ mean sales. As Table A6 reports, the estimation results are similar based on this alternative measure of market concentration.

${ }^{20}$ The additional controls included in the R\&D rate estimated equation are Tobin's Q and the level of sales as a share of the previous year's total assets. 


\section{B. Extensions}

We now extend our analysis in three directions. First, we examine whether a firm's distance to the technological frontier in its industry affects the relation between its markup and investment. Second, we study the effects of marker power on the labor share of income at the firm level. Third, we investigate how our results for the United States carry through to the other AEs in our sample.

\section{Distance to the technological frontier}

We begin by exploring how the relation between markups and investment is affected by a firm's relative technological status. In the model by Aghion and others (2005), the inverted$\mathrm{U}$ relation between higher market competition (the inverse of higher markups) and investment is steeper for industries composed of firms that, on average, are closer to the technological frontier. The reason for this is that for firms in such neck-and-neck industries, the escape-competition incentives are stronger, implying a steeper inverted-U curve. We now investigate whether this hypothesis is consistent with our firm-level data.

We define the distance to the technological frontier of the $i$ th firm as the difference between the $i$ th firm's TFP and the TFP of the firm with the highest TFP value in the respective sector in a given year. Our measure, distance $_{i j t}=\max \left(T F P_{j t}\right)-T F P_{i j t}$ is thus always positive except for the firm that is at the technological frontier. To compute this distance, we use our firm-level estimates of TFP. Recall that when we estimate the output elasticities used for the markup calculations, we also obtain firm-level TFP estimates.

The equation we estimate is an expanded version of equation (8) with two additional interaction terms: $\delta_{2}\left\{\ln \mu_{i j t} \times\right.$ distance $\left._{i j t}\right\}$ and $\gamma_{2}\left\{\ln \mu_{i j t} \times \ln \mu_{i j t} \times\right.$ distance $\left._{i j t}\right\}$. Note that this is the firm-level analog of the specification estimated by Aghion and others (2005) to test their model's prediction that in more neck-and-neck industries, that is, in those with low average technological distances, the inverted-U shape should be steeper. In terms of our specification, this hypothesis implies that the following cross-derivative should be negative: $\frac{\partial^{2} Y_{i j t}}{\partial \ln \mu_{i j t} \text { distance }_{i j t}}=\delta_{2}+2 \cdot \gamma_{2} \cdot \ln \mu_{i j t}<0$.

We present our estimates of the coefficients in Table 4. Based on the estimates of the coefficients and the expression for the cross-derivate already mentioned, we find that the value of the cross-derivative is, on average, negative. The cross derivative is negative if the markup is smaller than 1.87, a value well above the sample mean. This result implies that we find support for the notion that the inverted-U shape is steeper in more neck-and-neck cases.

In Figure 11, we provide a graphical representation of this result by plotting the inverted-U shape already reported in Figure 8 for high and low levels of technological distances. The resulting curve is indeed steeper for higher values of neck-and-neckness (smaller values of the technological gap). 


\section{Labor share}

To explore the relation between firm markups and the labor share, the estimated equation is as before, except that the term $Y_{i j t}$ now denotes the labor share. Investigating the relation of markups with the labor share is complicated by the lack of firm-level data for wages. To overcome this challenge, we construct the labor share using industry-level data for the average wage per employee, which we combine with firm-level data for employment and sales to compute a quasi-firm-level labor share. We take the industry-level data for the average wage per employee from the OECD STAN dataset, which is available for the AE countries in our sample. ${ }^{21}$

The relation between markups and this measure of the firm-level labor share is generally negative (Table 5). Unlike the relations for investment, the relation between higher markups and the labor share features a negative and statistically significant coefficient estimate of $\beta$ (column 1, row 1) and the relation is monotonic. As the level of market concentration increases, the negative relation between markups and the labor share grows stronger. Overall, these results are consistent with the conjecture of Autor and others (2017) that a rise in market power reduces the labor share.

\section{Investment, innovation, and labor share in other AEs}

Having assessed the relation of markups with investment, innovation, and the labor share for U.S. firms, we turn to firms in the 32 other AEs for which we have data. We re-estimate the afore-mentioned relations for these other 32 AEs included together in a panel. To control for country-specific macroeconomic developments, we augment equation (8) with country-time fixed effects, $\sum_{k t} \theta_{k t}$, where $k$ denotes the $k$ th country.

Table 6 reports the results for the most complete specifications including both interaction terms. The estimation results are qualitatively similar for firms in the United States and in other AEs, suggesting that the associated implications of rising market power have been broadly comparable.

\section{CONCLuSion}

This paper concludes that corporate market power has increased across a range of industries in advanced economies. Markups have been rising steadily since the 1980s, and at an accelerated pace since the mid-2000s. Measures of firm-level profitability and industry concentration have mirrored this increase in markups. Corporate level data suggest that these trends have been driven by a relatively small number of "superstar" firms in the upper tail of the distribution that are able to extract increasingly large markups.

\footnotetext{
${ }^{21}$ Compensation per employee is taken from the OECD STAN dataset. We allocate each STAN sector codes associated with sector-level compensation per employee with the 19 ICB sector codes in our Thomson Reuters Worldscope dataset. As before, to limit the effect of outliers, we apply 5 percent trimming to our labor share series, based on the country-sector-year distribution.
} 
Evidence from publicly listed firms in 33 advanced economies suggests that the rise in market power is influencing macroeconomic outcomes. There appears to be a non-monotonic relation between market power, market concentration, and investment (both on physical capital and R\&D). At low levels of markups, an increase in market power is associated with more investment, but eventually higher markups are associated with lower investment, particularly for companies operating in industries with high levels of market concentration. Higher markups and higher market concentration are also associated with a declining labor share. These results are consistent with the view that as companies increase their market power, they appropriate a growing share of the rents from production, leaving smaller returns accruing to labor. Increasing market power over recent decades may thus have contributed to the decline in the labor share.

The appropriate policy responses to this increase in market power depend on what drives it. We leave an exploration of the causes of rising market power for future work. In cases where barriers to entry are driving the increase in market power, and where that power is being used to, restrict supply, or engage in predatory pricing, antitrust policies could play important roles. At the same time, rising network and information externalities and increasing returns to scale may justify the existence of an oligopolistic structure in certain industries. 


\section{REFERENCES}

Ackerberg, D., K. Caves, and G. Frazer, 2015, "Identification Properties of Recent Production Function Estimators,” Econometrica, 83(6): 2411-51.

Aghion, P., N. Bloom, R. Blundell, R. Griffith, and P. Howitt, 2005, "Competition and Innovation: an Inverted-U Relation," The Quarterly Journal of Economics, 120(2): 70128.

Autor, D., D. Dorn, L. Katz, C. Patterson, and J. Van Reenen, 2017, "The Fall of the Labor Share and the Rise of Superstar Firms,” NBER Working Paper No. 23396.

Baqaee, D. R. and Farhi, E. (2017), "Productivity and Misallocation in General Equilibrium," NBER Working Paper 24007.

Baumol, W. (1982), "Contestable Markets: an Uprising in the Theory of Industry Structure," American Economic Review, 72(1):1-15.

Council of Economic Advisers, 2016. "Benefits of Competition and Indicators of Market Power." Issue Brief, Apr. 2016.

https://www.whitehouse.gov/sites/default/files/page/files/20160414_cea_competition_is sue_brief.pdf.

De Loecker, J., and J. Eeckhout, 2017, "The Rise of Market Power and the Macroeconomic Implications," NBER Working Paper No. 23687.

De Loecker, J., P. Goldberg, A. Khandelwal and N. Pavcnik, 2016, "Prices, Markups and Trade Reform," Econometrica, 84(2): 445-510.

De Loecker, J., and F. Warzynski, 2012, "Markups and Firm-Level Export Status," American Economic Review, 102(6): 2437:2471.

Díez, F., J. Fan, and C. Villegas-Sanchez (2018), “Global Declining Competition," forthcoming IMF Working Paper.

Eggertsson, G. B., Robbins, J. A., and Wold, E. G. (2018), "Kaldor and Pikettys facts: The Rise of Monopoly Power in the United States.” NBER Working Paper 24287.

Hall, Robert E., 1988, "The Relation between Price and Marginal Cost in U.S. Industry," Journal of Political Economy, 96(5): 921-47.

Karabarbounis, L., and B. Neiman, 2018, “Accounting for Factorless Income,” NBER Working Paper No. 24404. 
Shapiro, Carl, 2018. "Antitrust in a Time of Populism." International Journal of Industrial Organization, forthcoming.

Traina, J., 2018, "Is Aggregate Market Power Increasing? Production Trends Using Financial Statements" Stigler Center New Working Paper Series No 17. 
Figure 1. United States: Evolution of Estimated Markups (Sales-weighted mean for all publicly listed firms)

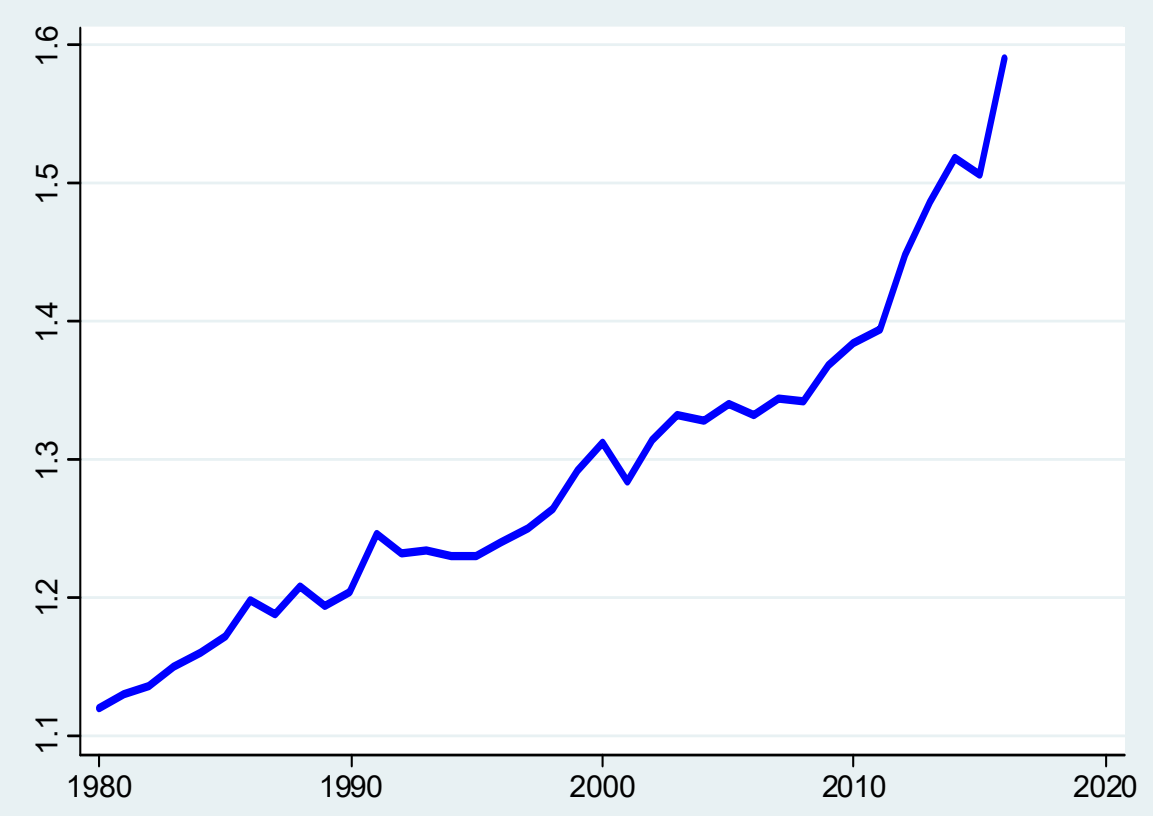

Source: Authors' estimates based on Thomson Reuters WorldScope data. 
Figure 2. U.S. Firms: Markups in 2016 vs. 1980 by Industry

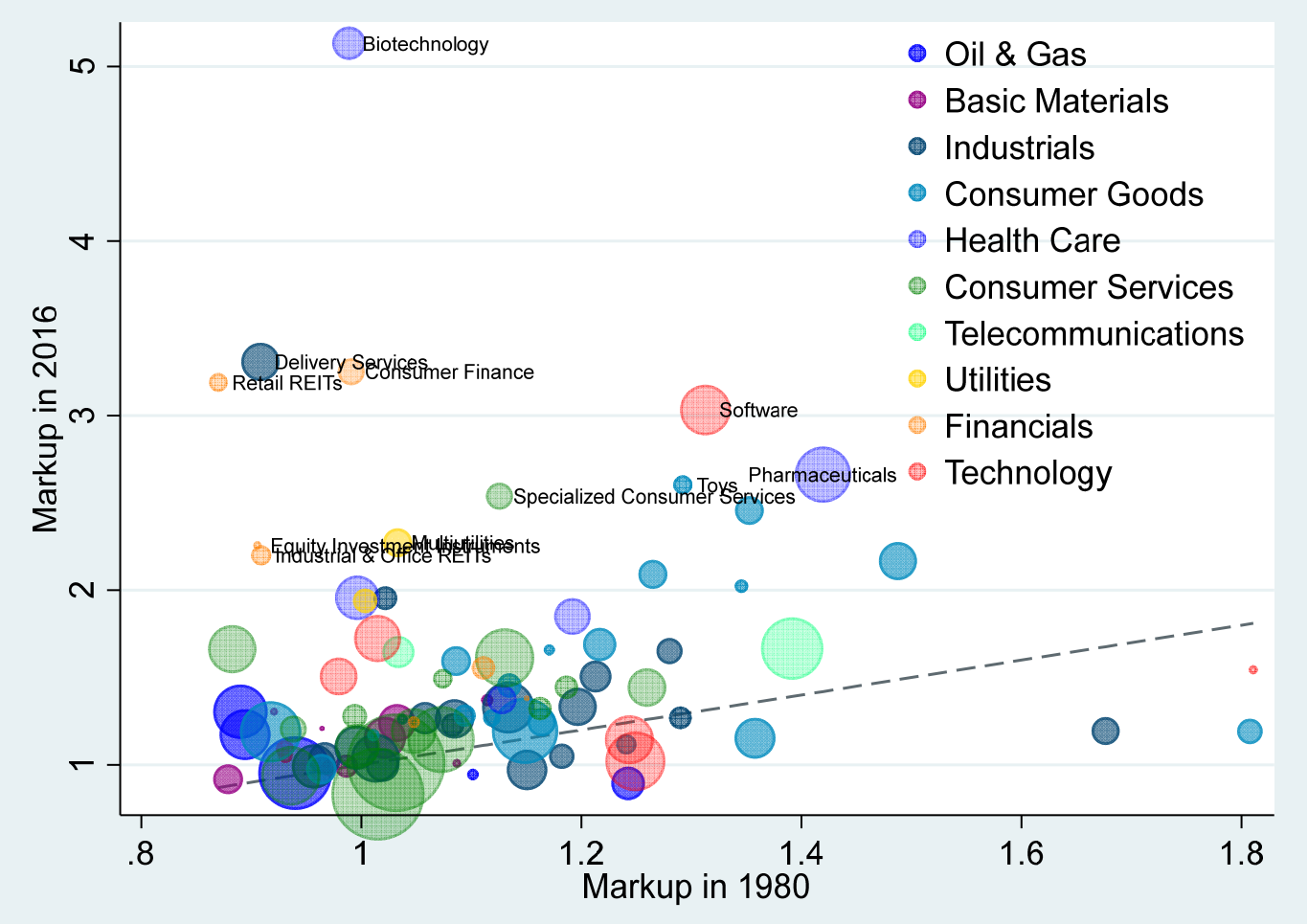

Note: Dashed line indicates 45-degree line along which markups are equal over time. Size of markers based on sales in 2016. Color of marker indicates ICB industry to which sub-sector belongs. 
Figure 3. U.S. Firms: Distribution of Markups, 1980 and 2016.

1. All U.S. firms

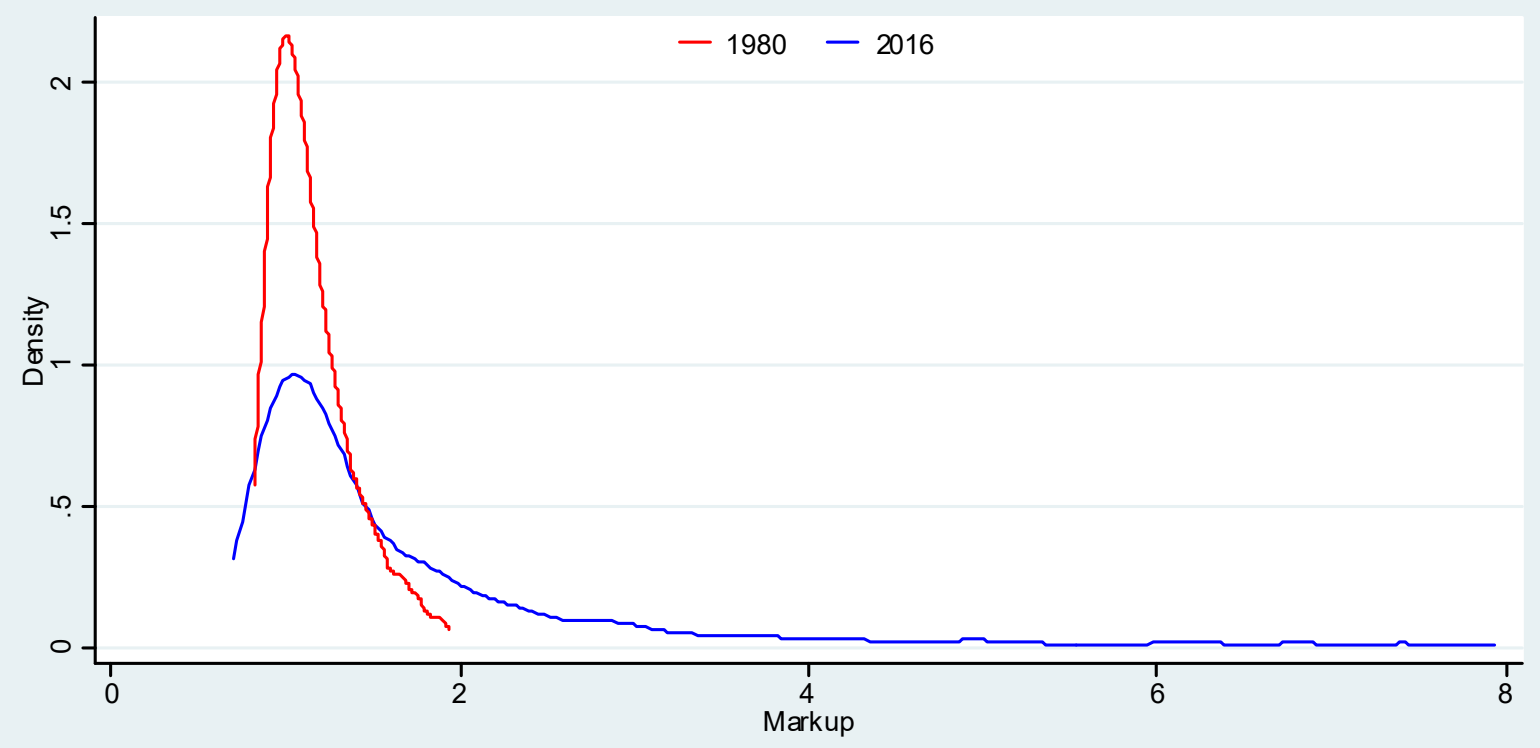

2. Firms by U.S. industry
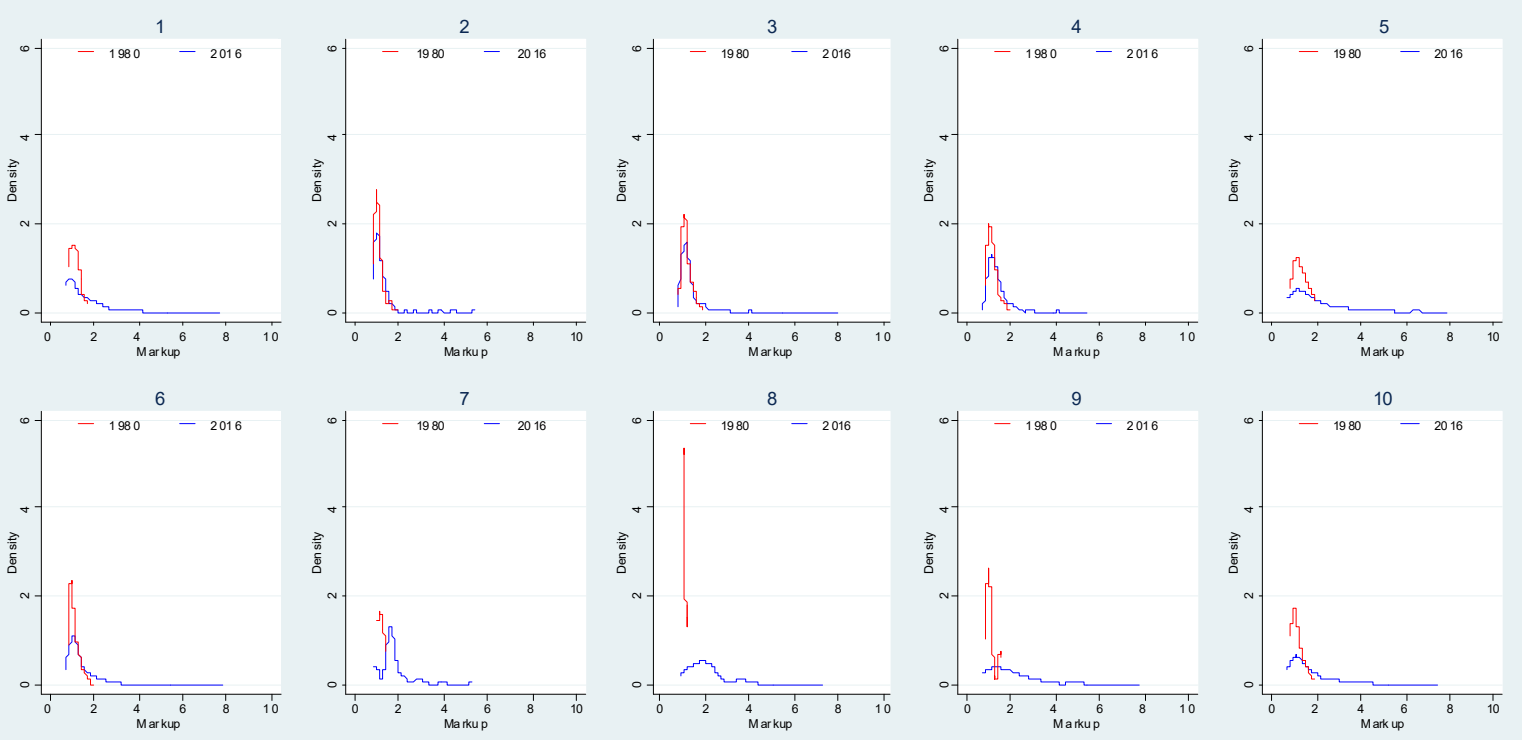

Note: Results for 10 industries of the FTSE/Dow Jones Industrial Classification Benchmark (ICB) available within Thomson Reuters Worldscope. 1 = Oil \& Gas; 2 = Basic Materials; $3=$ Industrials; 4 = Consumer Goods; 5 = Health Care; 6 = Consumer Services; 7 = Telecommunications; 8 = Utilities; 9 = Financials; $10=$ Technology . 
Figure 4. Estimates of Output Elasticity $\left(\beta_{x}\right)$ Over Time

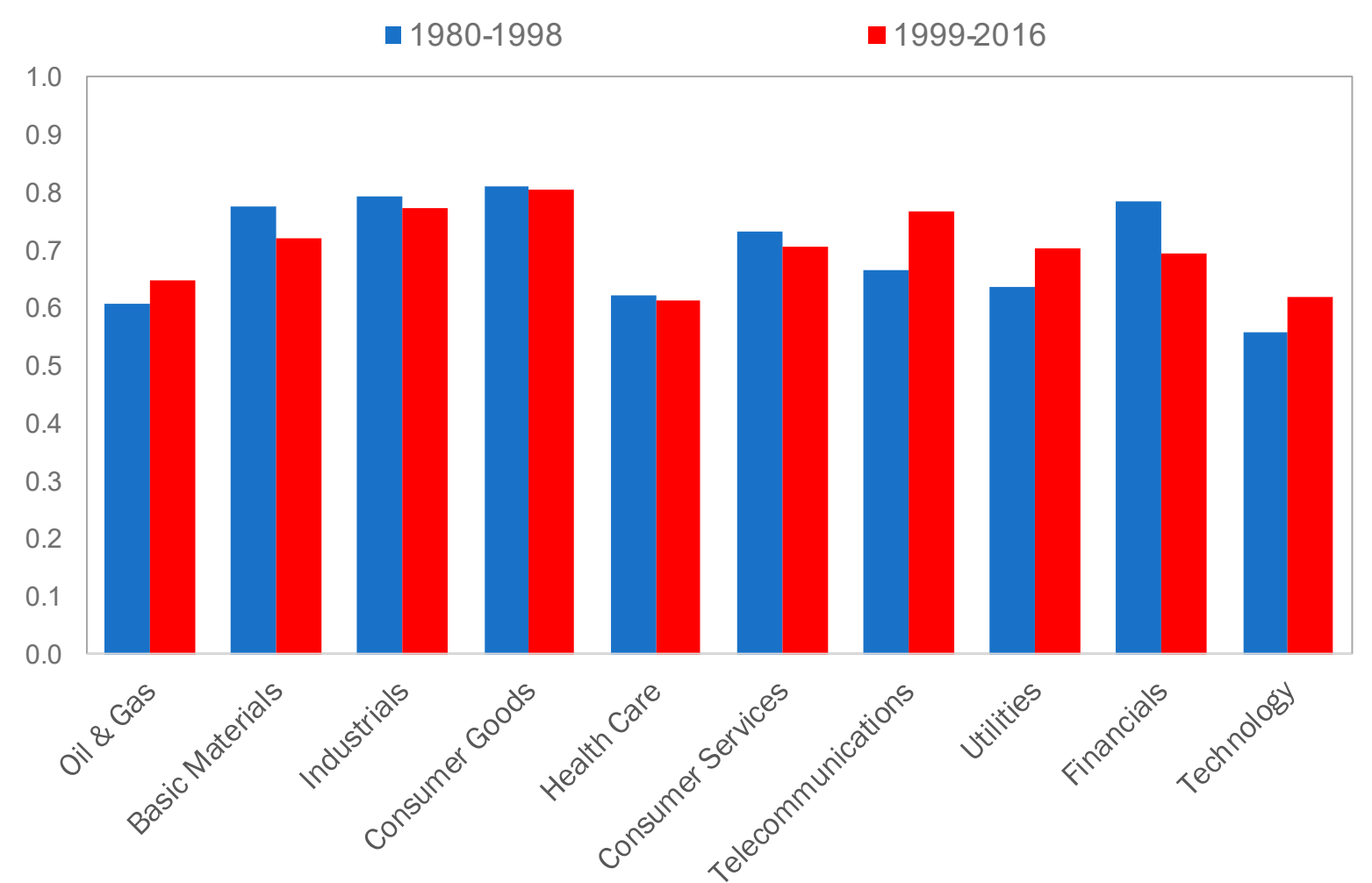

Note: U.S. data. Results for 10 industries of the FTSE/Dow Jones Industrial Classification Benchmark (ICB) available within Thomson Reuters Worldscope. 
Figure 5. Estimated Markups for U.S. Firms: Baseline and Alternative Approach

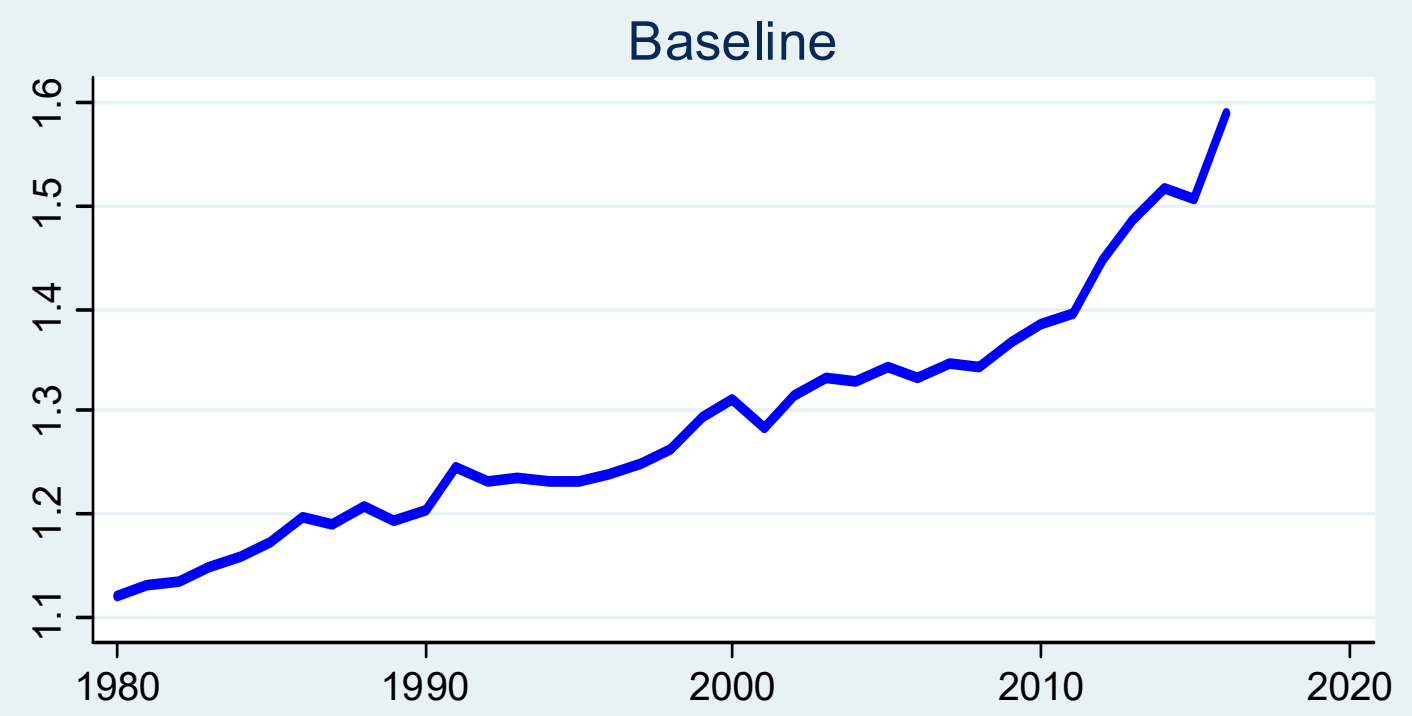

Controling for SGA

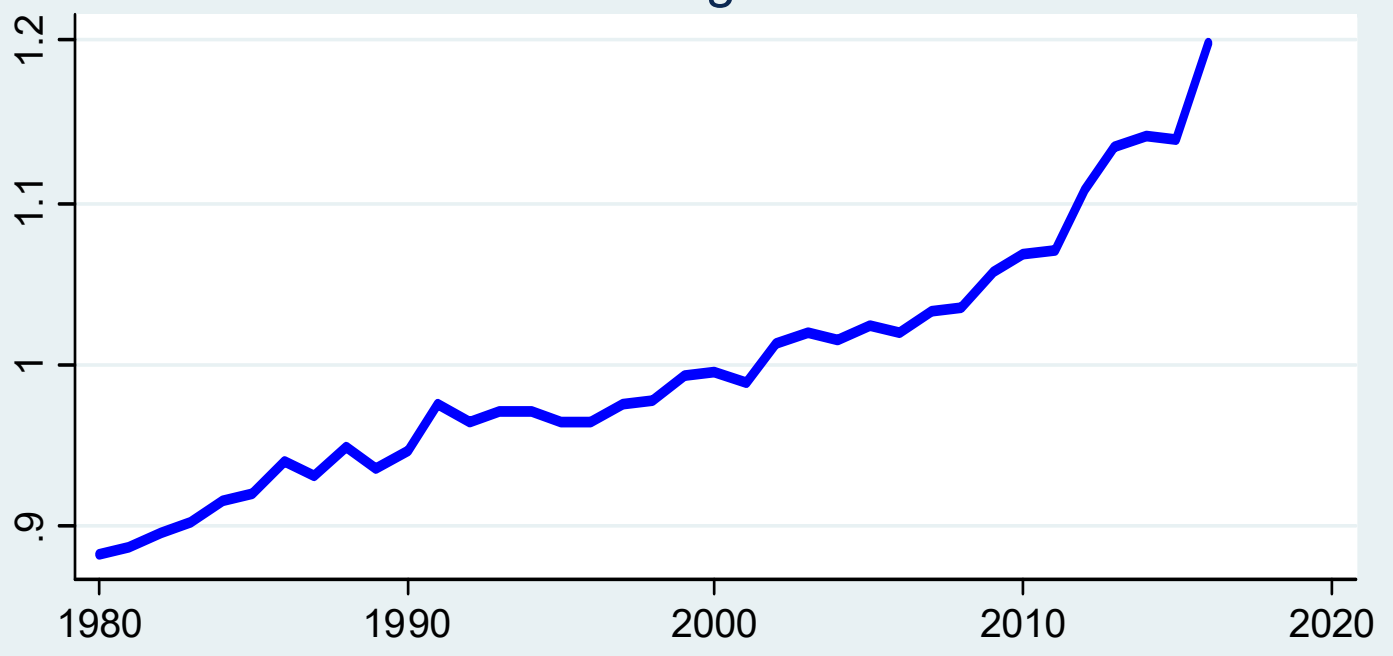

Note: Panel 2 reports estimate based on controlling for Selling, General and Administrative Expenses (SGA) as in equation (7). 
Figure 6. Evolution of Estimated Markups Across Economies (Sales-weighted mean for all publicly listed firms)
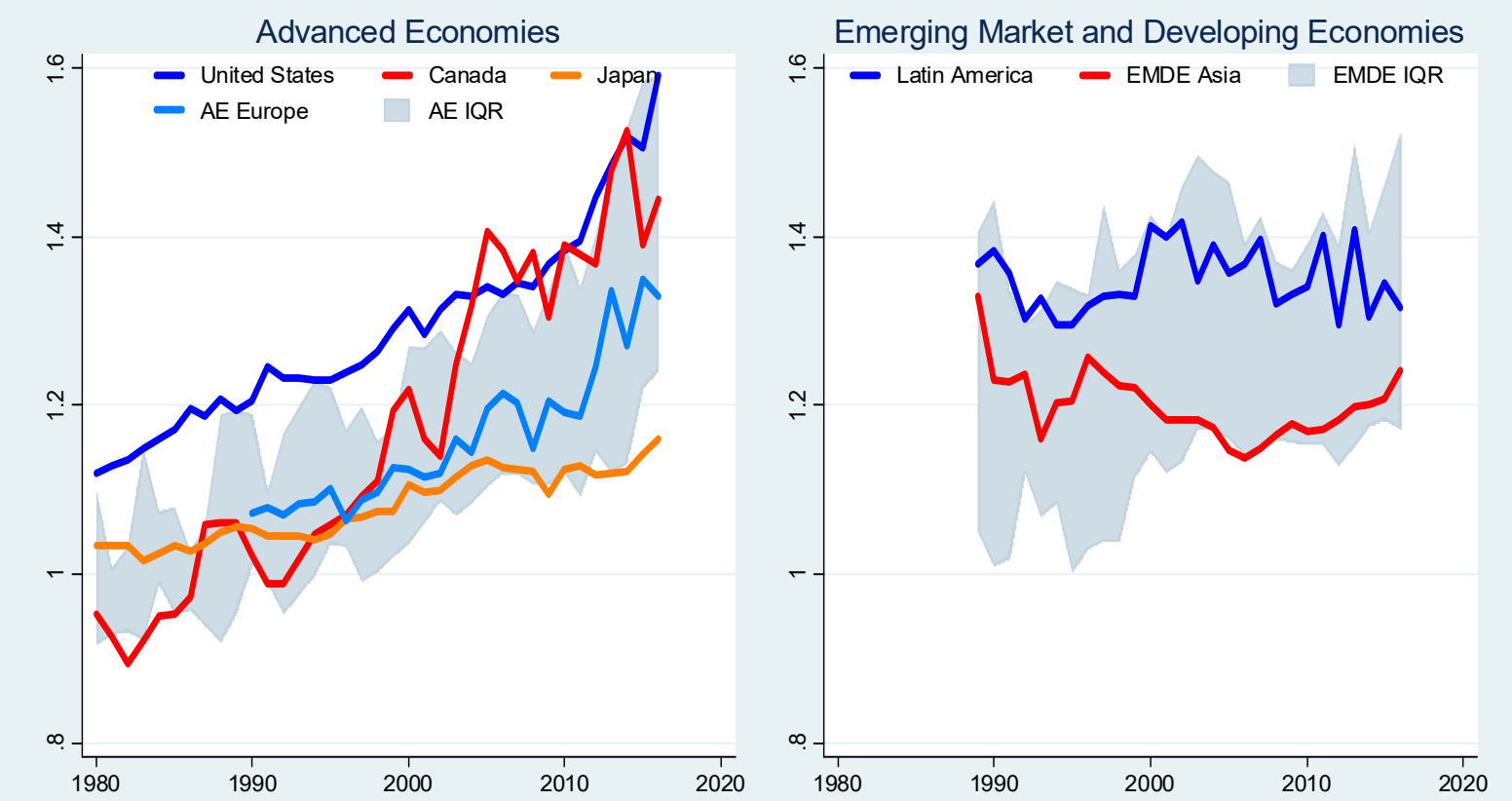

Note: Figure reports markup estimates for 33 advanced economies (AEs) and 41 emerging market and developing economies (EMDEs). For country groups (AE Europe, Latin America, and EMDE Asia) figure reports median of included countries. IQR denotes inter-quartile range. 
Figure 7. Firms in 32 Non-US AEs: Distribution of Markups, 1980 and 2016

\section{All firms}

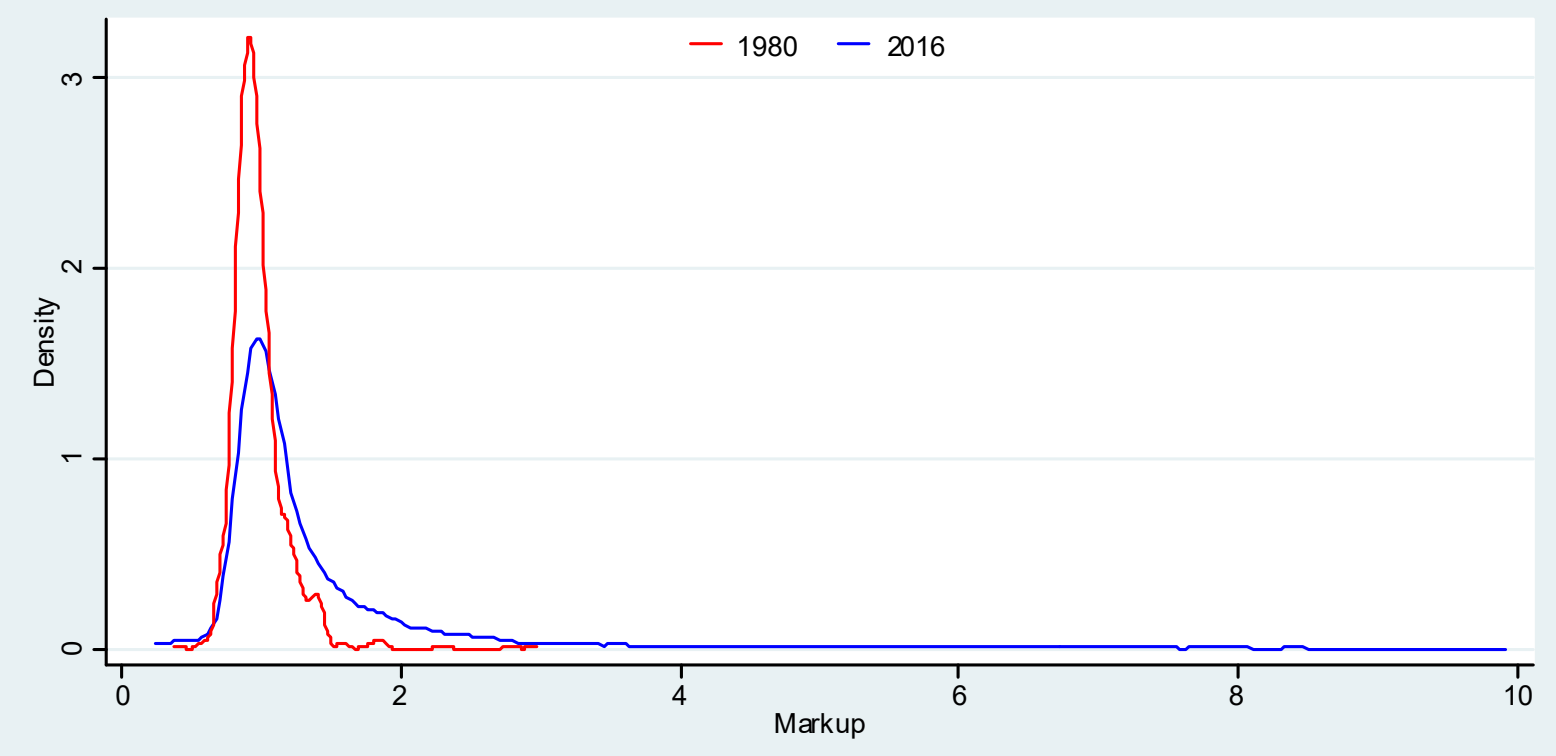

2. Firms by industry
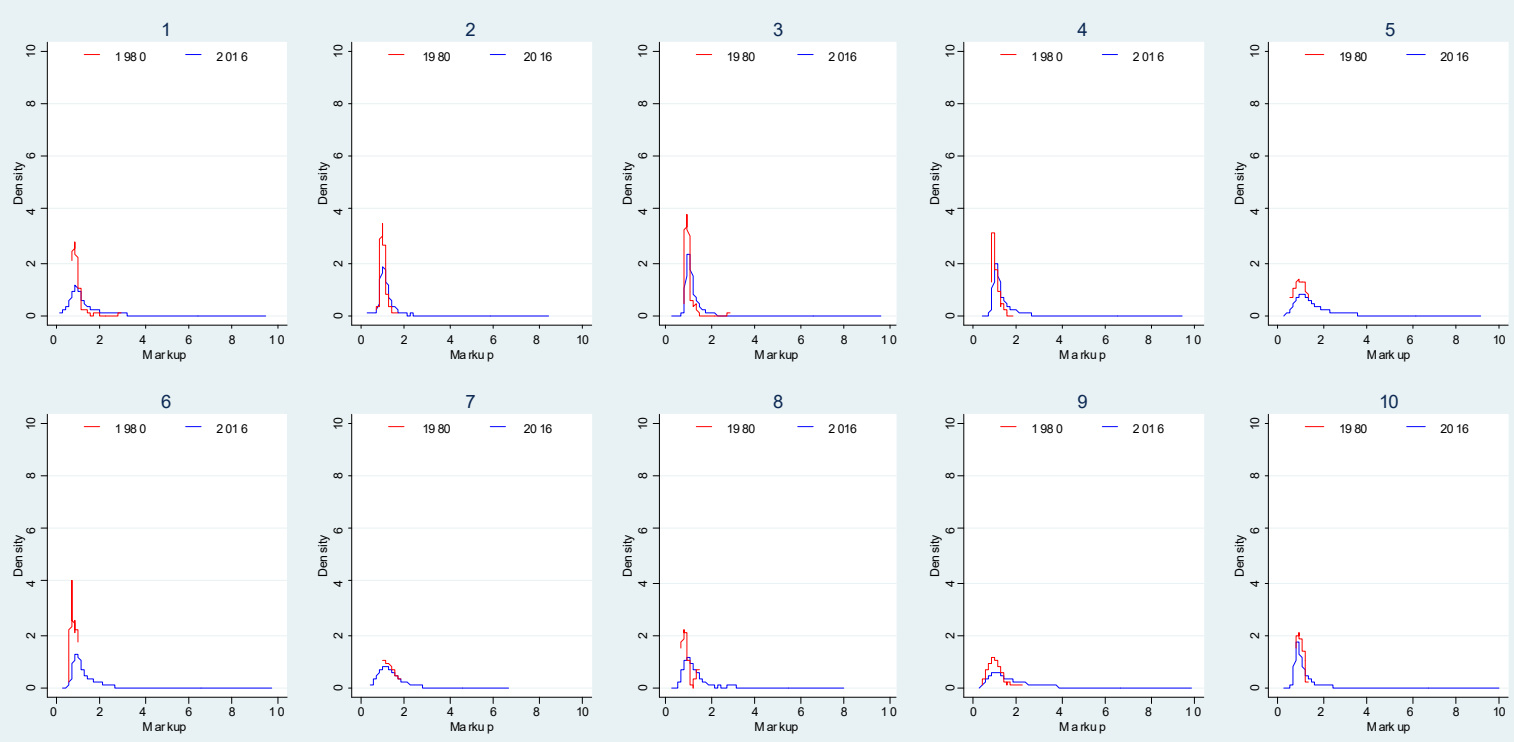

Note: Results for 10 industries of the FTSE/Dow Jones Industrial Classification Benchmark (ICB) available within Thomson Reuters Worldscope. 1 = Oil \& Gas; 2 = Basic Materials; 3 = Industrials; 4 = Consumer Goods; 5 = Health Care; 6 = Consumer Services; $7=$ Telecommunications; $8=$ Utilities; $9=$ Financials; $10=$ Technology. 
Figure 8. Investment Rate vs. Markup

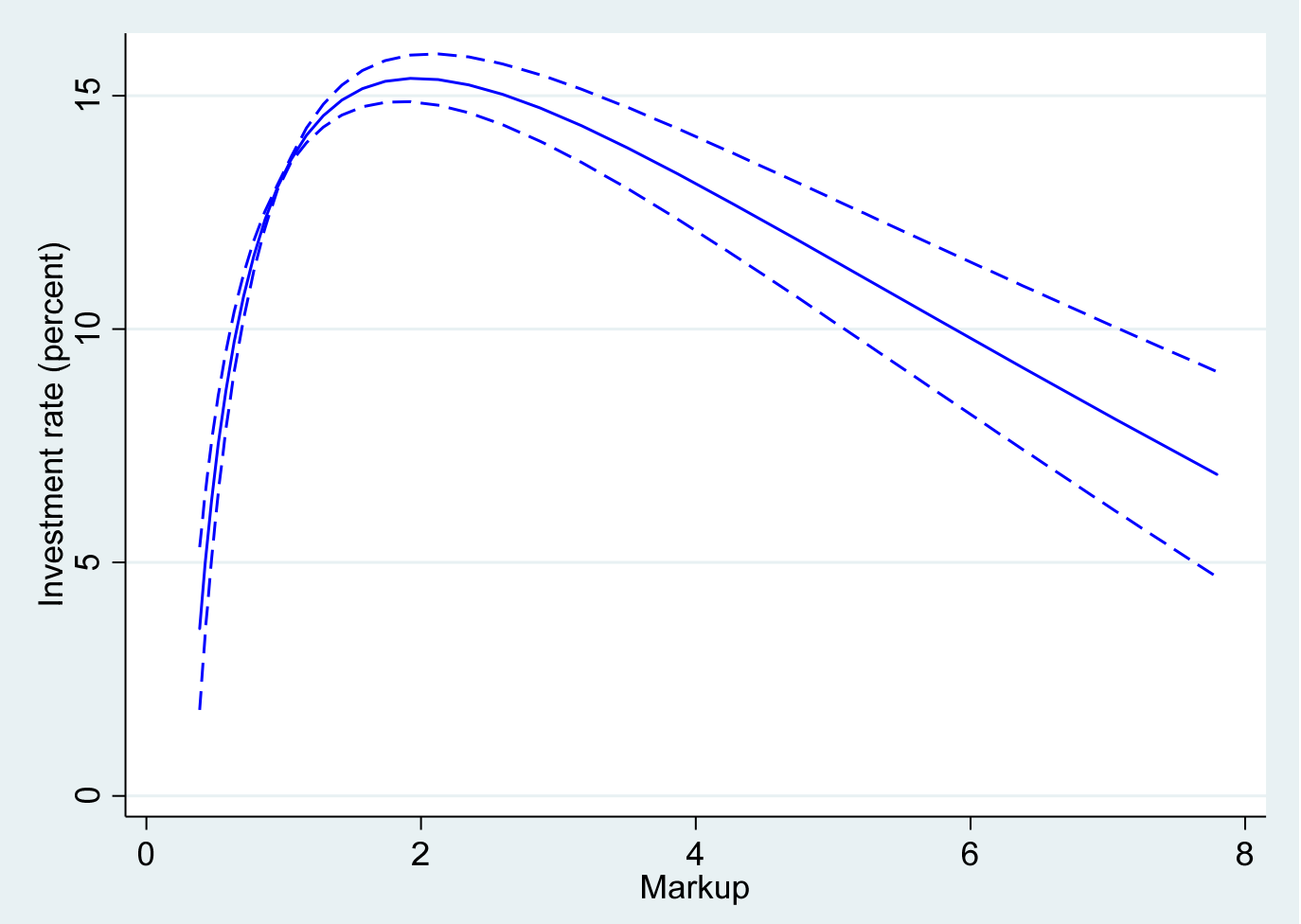

Note: Figure reports fitted value of investment rate vs. markup across sample range of markup based on estimates reported in Table 2 (column 1). Dashes indicate 90 percent confidence interval. 
Figure 9. Estimated Markup Coefficient $(\beta)$ vs. Market Concentration

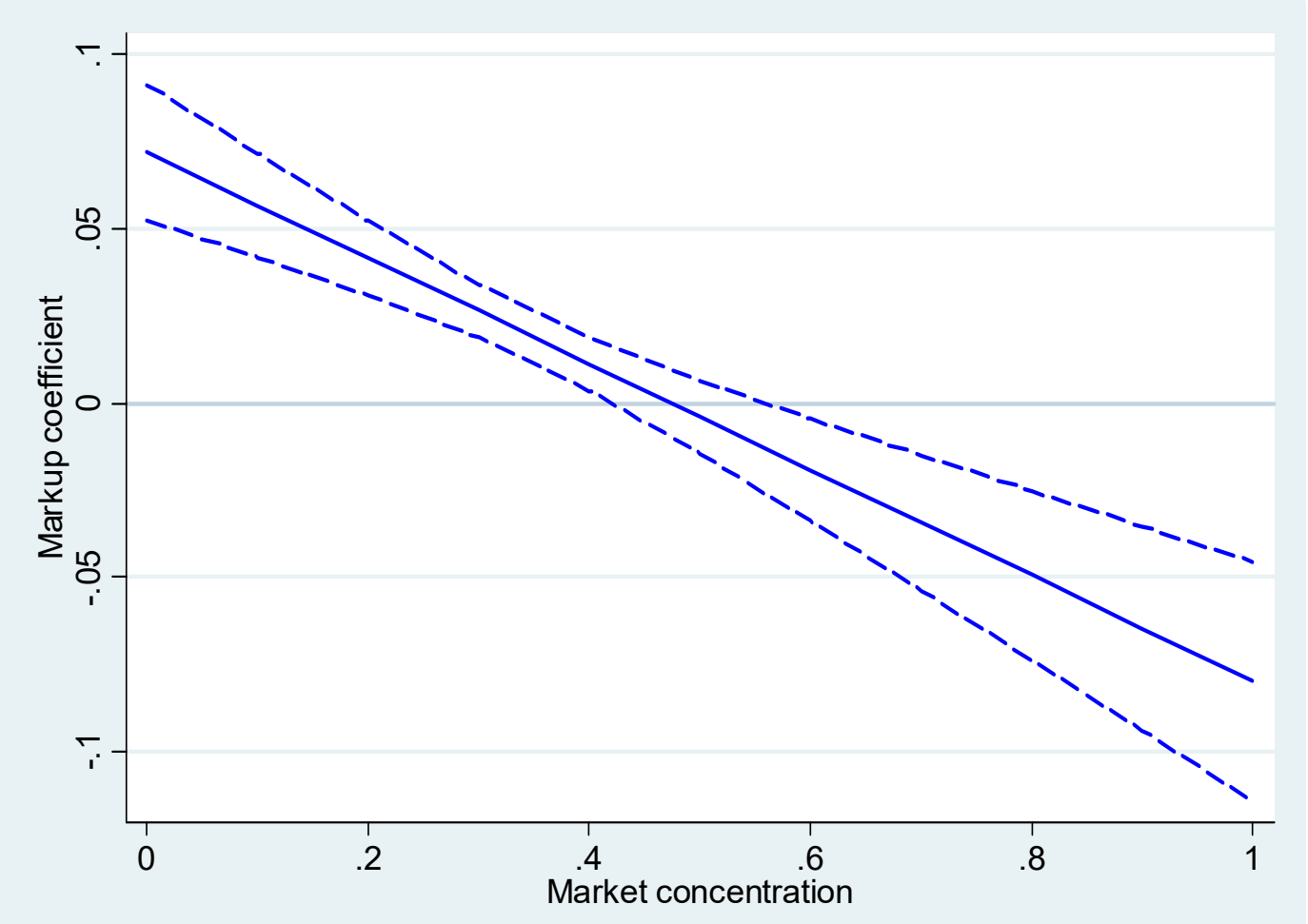

Note: Figure reports estimated composite coefficient on (log) firm markup across sample range of market concentration based on estimates reported in Table 2 (column 2). Dashes indicate 90 percent confidence interval. 
Figure 10. Marginal Association Between Markups and Investment Rate:

Distribution for U.S. Firms

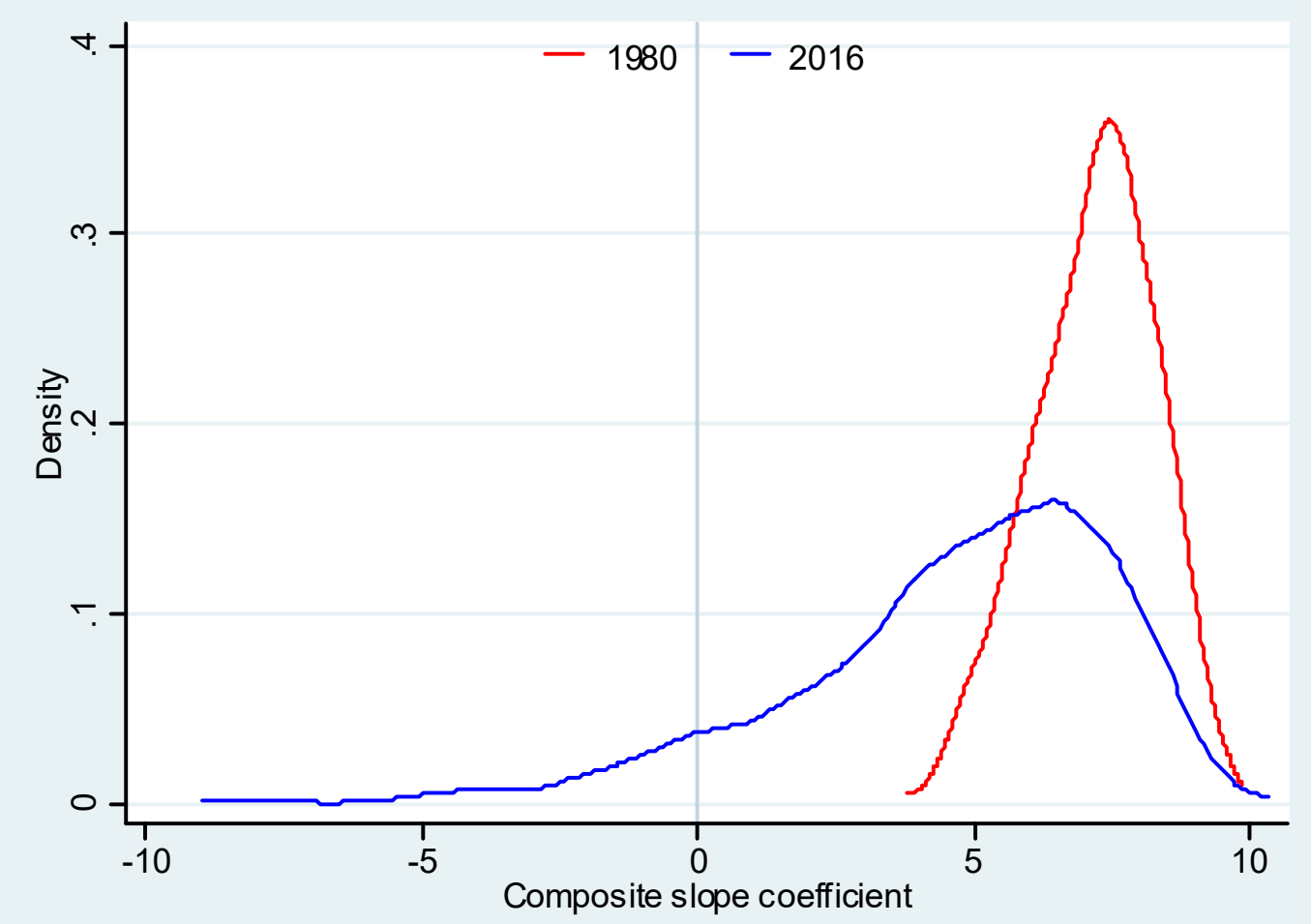

Note: Note: Marginal association between investment and markups is based on the composite slope coefficient $\frac{d Y_{i j t}}{d \ln \mu_{i j t}}=\beta+\delta \ln \mu_{i j t}+\gamma$ Concentration $_{i g t}$. The coefficient estimates are taken from Table 2 (column 3 ). 
Figure 11. Investment Rate vs. Markup by Distance to Technology Frontier

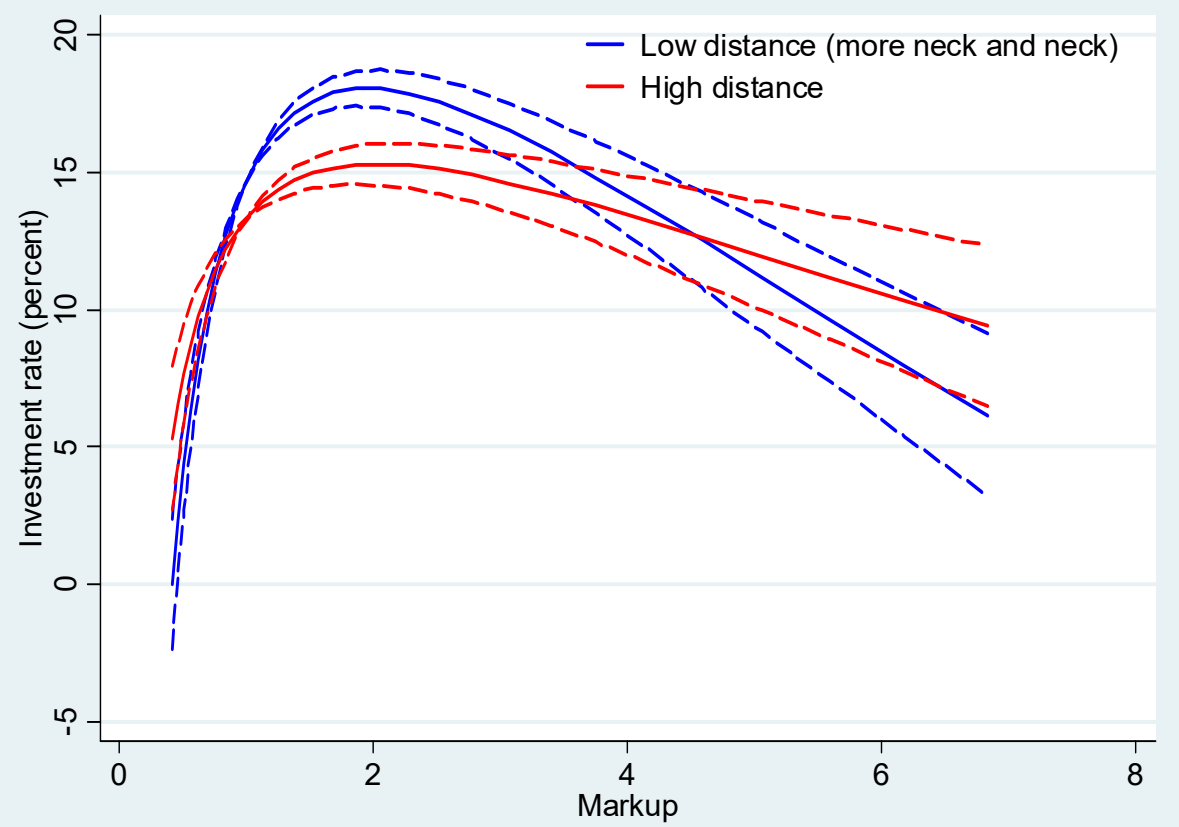

Note: U.S. data. High/low distance indicates technology gap of ith firm compared to TFP frontier (maximum) across all firms, by sub-sector and year, is in the top/lowest 5 percent of sample. 
Table 1. Relation Between Markup and Other Measures of Market Power

\begin{tabular}{lcc}
\hline & USA & Other AEs \\
\hline Dividend/sales & $1.923^{* * *}$ & $1.309^{* * *}$ \\
& $(0.233)$ & $(0.056)$ \\
Market cap/sales & $0.019^{* * *}$ & $0.016^{* * *}$ \\
& $(0.001)$ & $(0.001)$ \\
Concentration & $0.654^{* * *}$ & $0.135^{* * *}$ \\
& $(0.037)$ & $(0.014)$ \\
\hline
\end{tabular}

Note: Relation of firm markup with dividends-to-sales ratio and market capitalization-to-sales ratio estimated with firm and time-fixed effects (and heteroskedasticity-robust standard errors). Relation of markup aggregated at the sector level (sales-weighted mean) and concentration index (adjusted HHI) estimated with country- and time-fixed effects with standard errors clustered by sector. ${ }^{* * *} p<0.01,{ }^{* *} p<0.05,{ }^{*} p<0.1$. 
Table 2. Investment Rate Equation Estimates

\begin{tabular}{lccc}
\hline & $(1)$ & $(2)$ & $(3)$ \\
\hline Markup & $0.061^{* * *}$ & $0.072^{* * *}$ & $0.107^{* * *}$ \\
& $(0.007)$ & $(0.012)$ & $(0.012)$ \\
Markup $\times$ markup & $-0.045^{* * *}$ & & $-0.043^{* * *}$ \\
& $(0.005)$ & & $(0.005)$ \\
Concentration & & 0.025 & 0.022 \\
& & $(0.016)$ & $(0.015)$ \\
Markup $\times$ concentration & & $-0.152^{* * *}$ & $-0.131^{* * *}$ \\
& & $(0.031)$ & $(0.031)$ \\
Firm FE & & & \\
Time FE & Yes & Yes & Yes \\
Number of observations & 57,371 & 52,319 & 52,319 \\
$R^{2}$ & 0.228 & 0.221 & 0.224 \\
\hline
\end{tabular}

Note: U.S. data. Markup denotes log of markup of ith firm. Additional controls included (Tobin's $Q$ and salesto-lagged assets ratio in previous year). Heteroskedasticity-robust standard errors. ${ }^{* * *} p<0.01,{ }^{* *} p<0.05$, ${ }^{*}$ $\mathrm{p}<0.1$. 
Table 3. R\&D Rate Equation Estimates

\begin{tabular}{lccc}
\hline & $(1)$ & $(2)$ & $(3)$ \\
\hline Markup & $0.027^{* * *}$ & $0.036^{* * *}$ & $0.043^{* * *}$ \\
Markup $\times$ markup & $(0.004)$ & $(0.006)$ & $(0.007)$ \\
& $-0.009^{* *}$ & & $-0.008^{* *}$ \\
Concentration & $(0.003)$ & & $(0.004)$ \\
& & $0.014^{*}$ & $0.013^{*}$ \\
Markup $\times$ concentration & & $(0.007)$ & $(0.007)$ \\
& & $-0.048^{* * *}$ & $-0.045^{* * *}$ \\
& & $(0.016)$ & $(0.016)$ \\
Firm FE & & & \\
Time FE & Yes & Yes & Yes \\
Number of observations & Yes & Yes & Yes \\
$R^{2}$ & 59,470 & 54,627 & 54,627 \\
& 0.055 & 0.055 & 0.055 \\
\hline
\end{tabular}

Note: U.S. data. Markup denotes log of markup of ith firm. Additional controls included (Tobin's $Q$ and salesto-lagged assets ratio in previous year). Heteroskedasticity-robust standard errors. ${ }^{* * *} p<0.01,{ }^{* *} p<0.05,{ }^{*}$ $\mathrm{p}<0.1$. 
Table 4. Technology Gap, Markups, Investment, and R\&D

\begin{tabular}{lcc}
\hline Dependent variable & Investment & R\&D \\
\hline Markup & $0.104^{* * *}$ & $0.030^{* * *}$ \\
& $(0.010)$ & $(0.005)$ \\
Markup $\times$ markup & $-0.078^{* * *}$ & $-0.013^{* * *}$ \\
& $(0.009)$ & $(0.005)$ \\
Markup $\times$ Technology distance & $-0.035^{* * *}$ & -0.001 \\
& $(0.011)$ & $(0.005)$ \\
Markup $\times$ markup $\times$ Technology distance & $0.028^{* * *}$ & 0.003 \\
& $(0.010)$ & $(0.005)$ \\
Firm FE & & \\
Time FE & Yes & Yes \\
Number of observations & Yes & Yes \\
$R^{2}$ & 49,921 & 51,095 \\
& 0.237 & 0.059 \\
\hline
\end{tabular}

Note: U.S. data. Markup denotes log of markup of ith firm. Technology gap indicates ith firm's distance to the TFP frontier (maximum) across all firms in the subsector by year, an inverse measure of "neck-and-neckness." Heteroskedasticity-robust standard errors. ${ }^{* * *} \mathrm{p}<0.01,{ }^{* *} \mathrm{p}<0.05,{ }^{*} \mathrm{p}<0.1$. 
Table 5. Labor Share Equation Estimates

\begin{tabular}{lccc}
\hline & $(1)$ & $(2)$ & $(3)$ \\
\hline Markup & $-0.095^{* * *}$ & $0.128^{* * *}$ & $0.100^{* *}$ \\
& $(0.026)$ & $(0.038)$ & $(0.044)$ \\
Markup $\times$ markup & 0.009 & & 0.029 \\
& $(0.019)$ & & $(0.019)$ \\
Concentration & & $0.182^{* * *}$ & $0.182^{* * *}$ \\
& & $(0.053)$ & $(0.053)$ \\
Markup $\times$ concentration & & $-0.654^{* * *}$ & $-0.657^{* * *}$ \\
& & $(0.104)$ & $(0.104)$ \\
Firm FE & & & \\
Time FE & Yes & Yes & Yes \\
Number of observations & 87,129 & 80,888 & 80,888 \\
$R^{2}$ & 0.035 & 0.036 & 0.036 \\
\hline
\end{tabular}

Note: U.S. data. Markup denotes log of markup of $i$ th firm. Heteroskedasticity-robust standard errors. ${ }^{* * *}$ $p<0.01, * * p<0.05, * p<0.1$. 
Table 6. Firm-level Equation Estimates for the United States and Other AEs.

\begin{tabular}{lcccccc}
\hline & \multicolumn{2}{c}{ Investment } & \multicolumn{2}{c}{ R\&D } & \multicolumn{2}{c}{ Labor share } \\
& USA & non-US AE & USA & non-US AE & USA & non-US AE \\
\hline Markup & $0.107^{* * *}$ & $0.091^{* * *}$ & $0.043^{* * *}$ & $1.028^{* * *}$ & $0.100^{* *}$ & 0.065 \\
& $(0.012)$ & $(0.011)$ & $(0.007)$ & $(0.122)$ & $(0.044)$ & $(0.045)$ \\
Markup $\times$ markup & $-0.043^{* * *}$ & $-0.053^{* * *}$ & $-0.008^{* *}$ & $-0.356^{* *}$ & 0.029 & $-0.085^{*}$ \\
& $(0.005)$ & $(0.013)$ & $(0.004)$ & $(0.165)$ & $(0.019)$ & $(0.050)$ \\
Concentration & 0.022 & 0.013 & $0.013^{*}$ & $0.158^{* *}$ & $0.182^{* * *}$ & -0.018 \\
& $(0.015)$ & $(0.010)$ & $(0.007)$ & $(0.079)$ & $(0.053)$ & $(0.040)$ \\
Markup $\times$ concentration & $-0.131^{* * *}$ & $-0.061^{*}$ & $-0.045^{* * *}$ & $-1.033^{* * *}$ & $-0.657^{* * *}$ & $-0.229^{* *}$ \\
& $(0.031)$ & $(0.031)$ & $(0.016)$ & $(0.202)$ & $(0.104)$ & $(0.115)$ \\
Firm FE & & & & & & \\
Time FE & Yes & Yes & Yes & Yes & Yes & Yes \\
Time $\times$ country FE & Yes & & Yes & & Yes & \\
Observations & & Yes & & Yes & & Yes \\
$R^{2}$ & 52,319 & 72,616 & 54,627 & 70,661 & 80,888 & 64,799 \\
\hline
\end{tabular}

Note: Markup denotes log of markup of ith firm. Heteroskedasticity-robust standard errors. ${ }^{* * *} p<0.01,{ }^{* *}$ $p<0.05, * p<0.1$. 
Appendix Tables

Table A1. List of Countries in Sample

\begin{tabular}{|c|c|c|c|c|c|}
\hline $\begin{array}{l}\text { Advanced } \\
\text { economies }\end{array}$ & $N$ & $\begin{array}{l}\text { Emerging market } \\
\text { and developing } \\
\text { economies }\end{array}$ & $N$ & $\begin{array}{l}\text { Emerging market } \\
\text { and developing } \\
\text { economies }\end{array}$ & $N$ \\
\hline AUS & 23,874 & ARE & 605 & SRB & 902 \\
\hline AUT & 1,882 & ARG & 1,475 & THA & 9,364 \\
\hline BEL & 2,796 & BGR & 2,648 & TUR & 4,697 \\
\hline CAN & 29,142 & BHR & 229 & UKR & 912 \\
\hline $\mathrm{CHE}$ & 4,870 & BRA & 5,215 & VEN & 355 \\
\hline CZE & 558 & $\mathrm{CHL}$ & 3,068 & VNM & 6,385 \\
\hline DEU & 15,482 & $\mathrm{CHN}$ & 36,000 & ZAF & 5,537 \\
\hline DNK & 3,422 & $\mathrm{COL}$ & 861 & ZWE & 184 \\
\hline ESP & 3,554 & EGY & 1,878 & & \\
\hline EST & 189 & HRV & 925 & & \\
\hline FIN & 2,941 & HUN & 701 & & \\
\hline FRA & 16,784 & IDN & 6,433 & & \\
\hline GBR & 35,989 & IND & 27,350 & & \\
\hline GRC & 4,785 & JOR & 1,657 & & \\
\hline HKG & 13,968 & KAZ & 298 & & \\
\hline $\mathrm{IRL}$ & 1,357 & KEN & 386 & & \\
\hline ISL & 196 & KWT & 1,403 & & \\
\hline ISR & 5,418 & LBN & 48 & & \\
\hline ITA & 5,513 & LKA & 2,174 & & \\
\hline JPN & 80,690 & MAR & 728 & & \\
\hline KOR & 24,103 & MEX & 2,443 & & \\
\hline LTU & 335 & MUS & 338 & & \\
\hline LUX & 509 & MYS & 16,398 & & \\
\hline NLD & 4,334 & NGA & 723 & & \\
\hline NOR & 3,477 & OMN & 969 & & \\
\hline NZL & 2,047 & PAK & 3,457 & & \\
\hline PRT & 1,405 & PER & 1,463 & & \\
\hline SGP & 9,887 & $\mathrm{PHL}$ & 3,323 & & \\
\hline SVK & 257 & POL & 5,509 & & \\
\hline SVN & 510 & QAT & 321 & & \\
\hline SWE & 7,924 & ROU & 1,505 & & \\
\hline TWN & 24,427 & RUS & 5,842 & & \\
\hline USA & 133,231 & SAU & 1,236 & & \\
\hline
\end{tabular}

Note: Table reports list of countries in the sample, indicated by International Organization for Standardization (ISO) three-letter codes, and number of firm-year markup estimates obtained $(N)$. 
Table A2. Summary Statistics for Selected Variables

\begin{tabular}{lcccc}
\hline & \multicolumn{3}{c}{ Firm-level percentiles } & \\
\cline { 2 - 4 } Variable & 25th & 50 th & 75th & \multirow{2}{*}{$N$} \\
\hline Sales-to-COGS ratio & 1.18 & 1.39 & 1.85 & 717,958 \\
Investment rate (percent) & 2.81 & 7.09 & 17.22 & 294,418 \\
R\&D rate (percent) & 0.25 & 7.18 & 50.72 & 281,970 \\
Employment (number of employees) & 156 & 675 & 2,700 & 626,304 \\
\hline
\end{tabular}

Note: Table reports summary statistics for full sample of 74 economies as well as number of observations $(N)$ available for each variable.

Table A3. U.S. Firm-level Investment Equation Estimates: by U.S. Industry

\begin{tabular}{lll}
\hline Sector & Markup & Markup $\times$ markup \\
\hline Oil \& Gas & $0.094^{* * *}$ & $-0.060^{* *}$ \\
Basic Materials & $0.055^{* *}$ & $-0.044^{*}$ \\
Industrials & $0.111^{* * *}$ & $-0.048^{* * *}$ \\
Consumer Goods & $0.084^{* * *}$ & $-0.050^{* *}$ \\
Health Care & -0.006 & -0.002 \\
Consumer Services & $0.053^{* *}$ & $-0.037^{* *}$ \\
Telecommunications & 0.015 & -0.007 \\
Utilities & 0.045 & -0.012 \\
Financials & $0.081^{* *}$ & -0.058 \\
Technology & $0.068^{* * *}$ & $-0.054^{* * *}$ \\
& & \\
Firm FE & Yes & \\
Time FE & Yes & \\
Number of observations & 62,726 & \\
$R^{2}$ & 0.250 & \\
\hline
\end{tabular}

Note: Markup denotes log of markup of ith firm. Heteroskedasticity-robust standard errors. Results for 10 industries of the FTSE/Dow Jones Industrial Classification Benchmark (ICB) available within Thomson Reuters Worldscope. Additional controls and fixed effects included in estimated equation, as in Table 2 (column 1 ). Heteroskedasticity-robust standard errors. ${ }^{* * *} p<0.01,{ }^{* *} p<0.05,{ }^{*} p<0.1$. 
Table A4. U.S. Firm-level Equation Estimates: OLS and Instrumental Variables

\begin{tabular}{lcccc}
\hline & $(1)$ & $(2)$ & $(3)$ & $(4)$ \\
Dependent variable & Investment & Investment & R\&D & R\&D \\
Estimation procedure & OLS & IV & OLS & IV \\
\hline Markup & $0.061^{* * *}$ & $0.202^{* * *}$ & $0.027^{* * *}$ & 0.045 \\
& $(0.007)$ & $(0.060)$ & $(0.004)$ & $(0.027)$ \\
Markup $\times$ markup & $-0.045^{* * *}$ & $-0.228^{* * *}$ & $-0.009^{* *}$ & $-0.055^{* *}$ \\
& $(0.005)$ & $(0.054)$ & $(0.003)$ & $(0.027)$ \\
Firm FE & & & & \\
Time FE & Yes & Yes & Yes & Yes \\
Number of observations & 57,371 & 57,292 & 59,470 & 59,393 \\
$R^{2}$ & 0.228 & 0.181 & 0.055 & 0.019 \\
\hline
\end{tabular}

Note: U.S. data. Markup denotes log of markup of ith firm. Instrument for markup of $i$ th firm is median markup for other firms in same ICB sub-sector (excluding ith firm). Additional controls included in investment equation (Tobin's $Q$, sales-to-lagged capital ratio, and $R \& D$ rate in previous year) and $R \& D$ equation (Tobin's $Q$ and salesto-lagged assets ratio in previous year). Heteroskedasticity-robust standard errors. ${ }^{* * *} p<0.01,{ }^{* *} p<0.05$, * $\mathrm{p}<0.1$. 
Table A5. U.S. Firm-level Equation Estimates: Additional Fixed Effects

\begin{tabular}{lcccc}
\hline & $(1)$ & $(2)$ & $(3)$ & $(4)$ \\
Dependent variable & Investment & Investment & R\&D & R\&D \\
\hline Markup & $0.061^{* * *}$ & $0.061^{* * *}$ & $0.027^{* * *}$ & $0.027^{* * *}$ \\
& $(0.007)$ & $(0.007)$ & $(0.004)$ & $(0.004)$ \\
Markup $\times$ markup & $-0.045^{* * *}$ & $-0.041^{* * *}$ & $-0.009^{* *}$ & $-0.008^{* *}$ \\
& $(0.005)$ & $(0.005)$ & $(0.003)$ & $(0.003)$ \\
& & & & \\
Firm FE & Yes & Yes & Yes & Yes \\
Time FE & Yes & & Yes & \\
Time $\times$ sector FE & & Yes & & Yes \\
Number of observations & 57,371 & 57,371 & 59,470 & 59,470 \\
$R^{2}$ & 0.228 & 0.255 & 0.055 & 0.070 \\
\hline
\end{tabular}

Note: U.S. data. Markup denotes log of markup of $i$ th firm. Instrument for markup of $i$ th firm is median markup for other firms in same ICB sub-sector (excluding ith firm). Columns (2) and (4) include sector $\times$ time fixed effects. Additional controls included in investment equation (Tobin's $Q$, sales-to-lagged capital ratio, and R\&D rate in previous year) and $R \& D$ equation (Tobin's $Q$ and sales-to-lagged assets ratio in previous year). Heteroskedasticity-robust standard errors. ${ }^{* * *} p<0.01,{ }^{* *} p<0.05,{ }^{*} p<0.1$. 
Table A6. U.S. Firm-level Investment Rate Equation Estimates: Market Concentration Based on Mean-adjusted HHI Index

\begin{tabular}{lccc}
\hline & $(1)$ & $(2)$ & $(3)$ \\
\hline Markup & $0.072^{* * *}$ & $0.021^{* * *}$ & $0.015^{* * *}$ \\
& $(0.012)$ & $(0.004)$ & $(0.004)$ \\
Concentration & 0.025 & 0.003 & -0.007 \\
& $(0.016)$ & $(0.002)$ & $(0.007)$ \\
Markup $\times$ concentration & $-0.152^{* * *}$ & $-0.021^{* * *}$ & $-0.023^{* * *}$ \\
& $(0.031)$ & $(0.004)$ & $(0.007)$ \\
Firm FE & & & \\
Time FE & Yes & Yes & Yes \\
Number of observations & Yes & Yes & Yes \\
$R^{2}$ & 52,319 & 52,319 & 57,371 \\
& 0.221 & 0.221 & 0.227 \\
\hline
\end{tabular}

Note: Column (1) reports the baseline estimation results (as in Table 1, column 2). Column (2) reports baseline results with $\mathrm{HHI}$ index standardized (demeaned and scaled by reciprocal of standard deviation). Column (3) reports results for equation where market concentration is based on alternative $\mathrm{HHI}$ index, defined as $H_{j t}=$ $\sum_{i} s_{i j t}^{2}$ where $i$ represents a firm, $j$ represents sub-sectors (based on the 115 ICB sub-sectors available within Thomson Reuters Worldscope), $t$ represents a year, and $s_{i j t}$ represents the sales of firm $i$ in sector $j$ in year $t$ as a ratio of the sector $j$ mean of sales. For comparability of coefficient estimates across columns (2) and (3) this $\mathrm{HHI}$ index is also standardized. Markup denotes log of markup of $i$ th firm. Additional controls included (Tobin's $Q$, sales-to-lagged capital ratio, and R\&D rate in previous year). Heteroskedasticity-robust standard errors. ${ }^{* * *}$ $p<0.01, * * p<0.05, * p<0.1$. 